\title{
Boundary layer new particle formation over East Antarctic sea ice - possible Hg-driven nucleation?
}

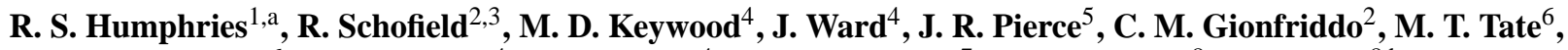 \\ D. P. Krabbenhoft ${ }^{6}$, I. E. Galbally ${ }^{4}$, S. B. Molloy ${ }^{4}$, A. R. Klekociuk ${ }^{7}$, P. V. Johnston ${ }^{8}$, K. Kreher ${ }^{8, b}$, A. J. Thomas ${ }^{8}$, \\ A. D. Robinson ${ }^{9}$, N. R. P. Harris ${ }^{9}$, R. Johnson ${ }^{10}$, and S. R. Wilson ${ }^{1}$ \\ ${ }^{1}$ Centre for Atmospheric Chemistry, University of Wollongong, Wollongong, Australia \\ ${ }^{2}$ School of Earth Sciences, University of Melbourne, Melbourne, Australia \\ ${ }^{3}$ ARC Centre of Excellence for Climate System Science, University of New South Wales, Sydney, Australia \\ ${ }^{4}$ CSIRO Ocean and Atmosphere Business Unit, Aspendale, Australia \\ ${ }^{5}$ Department of Atmospheric Science, Colorado State University, Fort Collins, Colorado, USA \\ ${ }^{6}$ United States Geological Survey, Wisconsin, USA \\ ${ }^{7}$ Australian Antarctic Division, Hobart, Australia \\ ${ }^{8}$ National Institute of Water and Atmospheric Research, Lauder, New Zealand \\ ${ }^{9}$ Centre for Atmospheric Science, Department of Chemistry, University of Cambridge, Cambridge CB2 1EW, England \\ ${ }^{10}$ Institute for Marine and Antarctic Studies, University of Tasmania, Hobart, Australia \\ anow at: CSIRO Ocean and Atmosphere Business Unit, Aspendale, Australia \\ ${ }^{b}$ now at: Bodeker Scientific, Alexandra, New Zealand
}

Correspondence to: R. S. Humphries (rsh615@uowmail.edu.au)

Received: 1 May 2015 - Published in Atmos. Chem. Phys. Discuss.: 16 July 2015

Revised: 7 October 2015 - Accepted: 11 November 2015 - Published: 2 December 2015

\begin{abstract}
Aerosol observations above the Southern Ocean and Antarctic sea ice are scarce. Measurements of aerosols and atmospheric composition were made in East Antarctic pack ice on board the Australian icebreaker Aurora Australis during the spring of 2012. One particle formation event was observed during the 32 days of observations. This event occurred on the only day to exhibit extended periods of global irradiance in excess of $600 \mathrm{~W} \mathrm{~m}^{-2}$. Within the single air mass influencing the measurements, number concentrations of particles larger than $3 \mathrm{~nm}\left(\mathrm{CN}_{3}\right)$ reached almost $7700 \mathrm{~cm}^{-3}$ within a few hours of clouds clearing, and grew at rates of $5.6 \mathrm{~nm} \mathrm{~h}^{-1}$. Formation rates of $3 \mathrm{~nm}$ particles were in the range of those measured at other Antarctic locations at $0.2-1.1 \pm 0.1 \mathrm{~cm}^{-3} \mathrm{~s}^{-1}$. Our investigations into the nucleation chemistry found that there were insufficient precursor concentrations for known halogen or organic chemistry to explain the nucleation event. Modelling studies utilising known sulfuric acid nucleation schemes could not simultaneously reproduce both particle formation or growth rates. Surprising correlations with total gaseous mercury (TGM)
\end{abstract}

were found that, together with other data, suggest a mercurydriven photochemical nucleation mechanism may be responsible for aerosol nucleation. Given the very low vapour pressures of the mercury species involved, this nucleation chemistry is likely only possible where pre-existing aerosol concentrations are low and both TGM concentrations and solar radiation levels are relatively high $\left(\sim 1.5 \mathrm{ng} \mathrm{m}^{-3}\right.$ and $\geq 600 \mathrm{~W} \mathrm{~m}^{-2}$, respectively), such as those observed in the Antarctic sea ice boundary layer in this study or in the global free troposphere, particularly in the Northern Hemisphere.

\section{Introduction}

Nucleation in the atmosphere is important for the formation of new aerosol particles, which, after growth, can affect the Earth's radiative balance both directly and indirectly through their action as cloud condensation nuclei $(\mathrm{CCN})$. The interaction between $\mathrm{CCN}$ and radiative forcing is currently one of the largest uncertainties inherent in our understanding of 
the global climate (IPCC, 2013). A recent study by Carslaw et al. (2013) suggested that the biggest gains in reducing this uncertainty will be achieved through the study of pristine natural aerosols.

The Antarctic and Southern Ocean regions are among the most under-studied locations on the planet, largely due to logistical difficulties posed by their remoteness and extreme conditions. In this region, regular measurements are restricted to mid-latitude stations on continents surrounding the Southern Ocean (e.g. Cape Grim, Australia), stations on sub-Antarctic islands (e.g. Macquarie Island) or Antarctic stations. Aerosol measurements in the Antarctic sea ice are particularly sparse, with only two measurements reported in the literature, both occurring in the Weddell Sea in the West Antarctic sector (Davison et al., 1996; Atkinson et al., 2012). There have been no reported aerosol measurements in the vast East Antarctic sea ice region, and as such, no characterisation of the loading there other than from model studies, which, at most, have been validated using data from continental stations. Recent results from this campaign (Humphries et al., 2015) have found that the Antarctic sea ice region is atmospherically distinct from both the adjacent continental and Southern Ocean atmospheres.

Aerosol nucleation is ubiquitous throughout the atmosphere, with burst events occurring in the boundary layer known as new particle formation (NPF) events. In the continental boundary layer where precursor sources are significant, NPF events are relatively common (Kulmala et al., 2004). In the marine boundary layer (MBL), however, NPFprecursor source strengths are lower and significant background aerosol populations exist (e.g. wind-produced sea salt), which scavenge precursor vapours, preventing gas-toparticle nucleation. Consequently, only a handful of NPF events have been observed in the remote MBL (e.g. Covert et al., 1996; Koponen et al., 2002; Heintzenberg et al., 2004). The Antarctic sea ice region has many characteristics of the remote MBL; however, the concentration of background wind-produced aerosol populations is significantly reduced due to the ice barrier between the ocean and atmosphere. Consequently, NPF events in the Antarctic sea ice boundary layer could be more likely than in the MBL given that precursors and other favourable environmental conditions (e.g. oxidants, high humidity) are present.

Presented here is the characterisation of a NPF event observed during the first measurements of aerosols in the East Antarctic sea ice region. The changes in aerosol concentration are assessed for rates of formation and growth, possible nucleation mechanisms and relations/interactions with gasphase mercury.

\section{Methods}

\subsection{Measurement platform}

Measurements were made aboard the Aurora Australis, the Australian Antarctic Division's flagship ice breaker that was commissioned for the second Sea Ice Physics and Ecosystems eXperiment (SIPEXII) - a dedicated springtime marine science voyage to the sea ice off the East Antarctic coast. Leaving Hobart, Australia, on 14 September 2012, it reached the sea ice edge 9 days later, before spending 52 days in the ice pack (south of $61.5^{\circ} \mathrm{S}$, between 112 and $122^{\circ} \mathrm{E}$ ). Within the ice pack, the ship traversed between eight ice floes that were used as temporary research stations (1-5 day periods anchored to the drifting ice floe). The voyage track, along with sea ice concentration, is shown in Fig. 1. On the 18 October, the day of the particle formation event under study, the ship was drifting slowly west with the pack ice at around 1 knot, with an approximate location of $\left(65.27^{\circ} \mathrm{S}\right.$, $\left.119.07^{\circ} \mathrm{E}\right)$.

The ship housed a collection of on-board sensors collectively known as the underway data set. Included in this data set were two (port and starboard) permanent standard meteorological stations mounted between 16 and $30 \mathrm{~m}$ above sea level (a.s.l.), depending on the sensor and ship draft. Data from these stations included atmospheric pressure, wind speed and direction (relative to ship, and corrected relative to Earth), relative humidity, air temperature, incoming global solar irradiance, photosynthetically active radiation, accumulated precipitation, as well as other useful parameters such as ship location, speed and direction (GPS), pitch and roll of the ship and sea temperature. Full data and meta-data are available through Reeve (2013).

Ocean capable inlets allowed for measurements of atmospheric trace gases during the ocean crossing, while logistical limitations meant aerosol measurements were only conducted in the sea ice zone for 32 days between 23 September and 25 October 2012.

\subsection{Aerosol measurements}

In situ number concentrations were measured using two condensation particle counters (CPCs) every second during the voyage time within the Antarctic sea ice zone (Humphries et al., 2014). Measurements of two different size ranges were made: particles with diameters larger than $3 \mathrm{~nm}\left(\mathrm{CN}_{3}\right.$; Model 3025A, TSI, Shoreview, MN, USA) and those larger than $10 \mathrm{~nm}\left(\mathrm{CN}_{10}\right.$; Model 3772, TSI, Shoreview, MN, USA). Operational and logistical constraints meant a comprehensive aerosol measurement suite was unable to be deployed.

Air was sampled from a $3 \mathrm{~m}$ high mast located on the starboard side of the forecastle (totalling approximately $12 \mathrm{ma}$ as.l.) at a rate of $130 \mathrm{Lmin}^{-1}$ (to minimise loss via diffusion) through $19 \mathrm{~m}$ of $55 \mathrm{~mm}$ diameter antistatic tubing. An additional $2.7 \mathrm{~m}$ of $1 / 4^{\prime \prime}$ conductive tubing were 


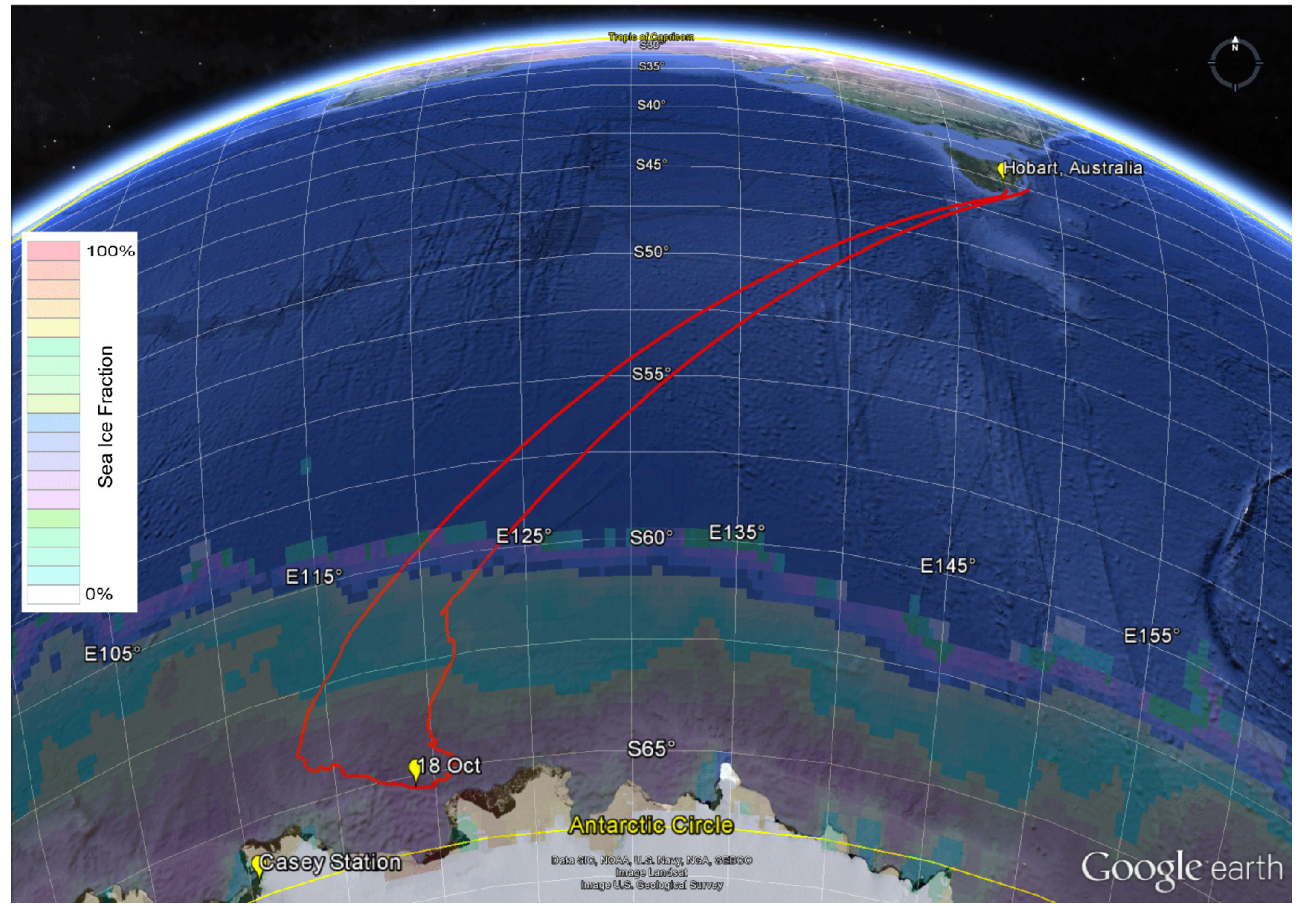

Figure 1. Ship track (red) relative to the departing port (Hobart, Australia) and the Antarctic continent. Sea ice concentration is shown in colours around the continent and is derived from Extended Reconstructed Sea Surface Temperature (ERSST) Version 3b, October 2012 mean. Imagery: Google Earth.

connected into the laboratory and split the flow to both CPCs. The long inlet (used for logistical reasons) led to losses that were calibrated post-voyage against a laboratory reference inlet (designed for minimal loss) to yield a relative transmission efficiency of 0.89 . The absolute losses were also calculated using two aerosol loss calculators: the first described by von der Weiden et al. (2009), while the second was written by Baron, P.A. and is available online (http://aerosols.wustl.edu/AAARworkshop08/software/ AEROCALC-11-3-03.xls). Both calculators give similar results. For particles above $10 \mathrm{~nm}$, calculated absolute inlet efficiencies ranged from 0.8 to 0.99 . Consequently, the experimentally derived transmission efficiency of 0.89 was deemed suitable for this size range and applied to the data. For sizes below $10 \mathrm{~nm}$, calculated inlet efficiencies decreased rapidly from around 0.8 at $10 \mathrm{~nm}$, down to 0.3 at $3 \mathrm{~nm}$. However, these calculations are not valid in the laminar-turbulent flow transition regime in which this inlet system lies. Additionally, results of inlet characterisation experiments showed significant variations that led to unreliable calibration factors in this size range. Consequently, application of these calculated inlet efficiencies would be unlikely to result in more accurate data due to the high uncertainty in this size range. Instead, the same factor of 0.89 was applied to this size range and hence the results presented here are considered a lower bound for actual number concentrations.
Aerosol data were filtered to remove the significant influence of ship exhaust to achieve a data set reflective of background aerosol loading. Filtering was performed by removal of data when relative wind directions were between 150 and $270^{\circ}$ (assuming $0^{\circ}$ is the bow of the ship). The influence of recirculated ship exhaust was also considered by analysis of ozone $\left(\mathrm{O}_{3}\right)$ concentrations (Klekociuk et al., 2015) and back trajectories. The absence of any significant decreases in $\mathrm{O}_{3}$, which is titrated out by $\mathrm{NO}_{x}$ in the ship exhaust, confirmed that recirculation did not affect our data set.

$\mathrm{CN}_{3}$ and $\mathrm{CN}_{10}$ data can be used to calculate other parameters that are useful for data interpretation. Taking the difference between these two measurements resulted in the number concentration of nanoparticles $\left(3-10 \mathrm{~nm} ; \mathrm{CN}_{3-10}\right)$ recently formed from gas-to-particle conversion. The parameter $\left(\mathrm{CN}_{3}-\mathrm{CN}_{10}\right) / \mathrm{CN}_{10}$ has been shown before (Warren and Seinfeld, 1985; Covert et al., 1992) to allow new particle formation to be easily distinguished from background concentrations and has also been calculated for the current data set.

Although the size information available from these measurements is basic, it is sufficient to estimate the growth rate using established equations (Kulmala et al., 2004). These equations result in good approximations under the assumption that the calculation period uses data measured within a single air mass - a good assumption in this case, as will be demonstrated later. Using this calculation, growth is found to 
occur in situ if changes in the number concentration of particles larger than $10 \mathrm{~nm}$ were delayed relative to changes in the number concentration of 3-10 nm particles.

\subsection{Trace-gas measurements}

Measurements of various trace gases occurred during both ocean and sea ice sections of the voyage. Sample inlets for these measurements were located fore of the exhaust at approximately $18 \mathrm{ma}$ a.s.l. This position meant that winds between 60 and $190^{\circ}$ (assuming $0^{\circ}$ is the bow of the ship) sampled ship exhaust directly. These values were filtered out using wind direction and wind speed $(<5$ knots) data.

One minute averages of in situ $\mathrm{O}_{3}$ (Galbally et al., 2014) were measured with a dual cell ultraviolet ozone analyser (Thermoelectron 49C), sampling through a particle filtered $30 \mathrm{~m}$ length of $1 / 4^{\prime \prime}$ Teflon tube. The instrument was calibrated to a traceable ozone standard before and after the voyage, and zeroed weekly during the voyage using an inline $\mathrm{O}_{3}$ scrubber for $30 \mathrm{~min}$.

Six halocarbons, including $\mathrm{CH}_{3} \mathrm{I}, \mathrm{C}_{2} \mathrm{Cl}_{4}, \mathrm{CH}_{3} \mathrm{CCl}_{3}$, $\mathrm{CHCl}_{3}, \mathrm{CH}_{2} \mathrm{Br}_{2}$ (co-eluted with $10-30 \% \mathrm{CHBrCl}_{2}$, Robinson et al., 2014b) and $\mathrm{CHBr}_{3}$, were measured (Robinson et al., 2014a) using a gas chromatograph with electron capture detector (GC-ECD, $\mu$ Dirac, Gostlow et al., 2010) via a particle filtered $60 \mathrm{~m}$ length $1 / 4^{\prime \prime}$ Teflon tube at a rate of $1 \mathrm{~L} \mathrm{~min}^{-1}$. Helium (99.995\% purity) and $\mathrm{N}_{2}(99.998 \%$ purity) were used as carrier and detector make-up gases. The GC-ECD analysed approximately 20 samples per day. Blanks and calibration chromatograms were run after every four sample chromatograms. The calibration air was drawn from a cylinder of clean natural air, previously filled at $\mathrm{Ni}$ wot Ridge (Colorado, USA) at an elevation of $3.5 \mathrm{~km}$ a.s.l. and enriched as needed with known concentrations of the target compounds. The cylinder was supplied by the Earth System Research Laboratory (ESRL) within the National Oceanic and Atmospheric Administration (NOAA) so that the reported mixing ratios are linked directly to the NOAA halocarbon calibration scales.

Total gaseous mercury (TGM) was measured (Gionfriddo et al., 2014) at 5 min intervals using a gold trap mercury analyser (Tekran Model 2537, Tekran Instruments Corporation, Toronto, Canada ${ }^{1}$ ). The inlet consisted of an inline particulate filter housed in a large (diameter $\sim 30 \mathrm{~cm}$ ) stainless steel can to protect against rain, snow, sea spray and major impacts from nearby crane activity. Sample air was drawn from the inlet through a $35 \mathrm{~m}$ heated Teflon sample line into the heated laboratory where the analyser was housed. The instrument was purged with argon (Ar; $99.999 \%$ purity) via $1 / 4^{\prime \prime}$ Teflon tubing. Calibration was performed every $24-48 \mathrm{~h}$ using an internal mercury source that was checked before and after the voyage at the supplying laboratory.

\footnotetext{
${ }^{1}$ Use of trade or product names does not constitute endorsement by the US Government.
}

Trace-gas profiles of the boundary layer were measured using Multi-AXis Differential Optical Absorption Spectrometry (MAX-DOAS). The MAX-DOAS collects spectra of scattered sunlight at different elevation angles above azimuth to determine vertical atmospheric profiles. The instrument was custom designed and built in-house at the National Institute of Water and Atmospheric Research (NIWA; Lauder, New Zealand). Full details of the instrument set-up are described by Schofield et al. (2014). The instrument was set up to scan two separate wavelength regions in the UV-Vis (ultraviolet to visible) spectrum, enabling retrieval of $\mathrm{NO}_{2}$, $\mathrm{O}_{3}, \mathrm{O}_{4}, \mathrm{BrO}, \mathrm{HCHO}, \mathrm{H}_{2} \mathrm{O}$ and IO. Spectra were measured at multiple viewing angles during different periods but included $-5,1,2,3,4,6,8,15,30$ and $90^{\circ}$ (with the latter being used as the reference angle). Viewing angles were maintained throughout the ship's roll using active correction utilising a ship-mounted accelerometer together with the built-in stepper motor. Due to the spectroscopic nature of this technique, data were filtered when reference spectra contained high amounts of $\mathrm{NO}_{2}$ (ship exhaust signature). The entrance optics were cleaned daily with lint-free paper towels.

\subsection{Trajectory analyses}

Back trajectories were calculated (Klekociuk and Schofield, 2014) using NOAA's HYSPLIT (HYbrid Single-Particle Lagrangian Integrated Trajectory) model (Draxler and Hess, 1998). The trajectories were calculated using the standard Global Data Assimilation System (GDAS) meteorological data available via the web interface and confirmed with the National Centre for Environmental Protection (NCEP) reanalysis data set. Vertical motion was calculated using model vertical velocity mode. Trajectories were initiated at heights of 10, 500 and $1000 \mathrm{~m}$ a.s.l. at the ship's location during the time surrounding the 18 October particle formation event. Each calculation estimated hourly three-dimensional air-parcel locations within the specified time frame.

At the high latitudes of the Antarctic, reanalysis data sets used to calculate trajectories rely on sparse meteorological measurements, resulting in high uncertainties, particularly when run for multiple days. Trajectories were therefore restricted to $72 \mathrm{~h}$, which limited the resulting uncertainty.

\subsection{Hydroxyl radical, $\mathrm{OH}$}

$\mathrm{OH}$ concentration on the 18 October was calculated from values of $J\left(\mathrm{O}^{1} \mathrm{D}\right)$ (the rate of production of excited oxygen atoms due to ozone photolysis) using the method described by Creasey et al. (2003). $J\left(\mathrm{O}^{1} \mathrm{D}\right)$ was not measured directly; however, using the relationship modified from Wilson (2015), it can be calculated such that

$J\left(\mathrm{O}^{1} \mathrm{D}\right)=2\left(\sum_{i} A_{i} \exp \left(-\frac{B_{i}}{\cos \theta}\right)\right) \cdot\left(\frac{\mathrm{O}_{3}^{\mathrm{sat}}}{300}\right)^{-\mathrm{RAF}}$, 
where $\theta$ is the solar zenith angle, $\mathrm{O}_{3}^{\text {sat }}$ is the total ozone column retrieved from satellite for the measurement day, and $A_{i}, B_{i}$ and RAF (Radiation Amplification Factor) are derived experimentally and are given in the literature cited above. The equation given by Wilson (2015) is suitable for low albedo regions, such as the Southern Ocean; however, over the dense pack ice, the high albedo surface increases the actinic flux significantly. The multiplication factor of 2 leading the equation is used to roughly correct for this elevated albedo. $\mathrm{O}_{3}^{\text {sat }}$ was 3 . derived from satellite measurements using the ozone monitoring instrument (OMI) (http://www.esrl.noaa.gov/) to be 441 Dobson units during the event day. Under a clear-sky assumption, this resulted in a $J\left(\mathrm{O}^{1} \mathrm{D}\right)$ of $1.2 \times 10^{-5} \mathrm{~s}^{-1}$. Through consideration of the reaction chemistry (e.g. primary sink mechanisms using $[\mathrm{CO}]=60 \mathrm{ppbv}$ and $\left[\mathrm{CH}_{4}\right]=1.8 \mathrm{ppmv}$ [http: //ds.data.jma.go.jp/gmd/wdcgg/]), the midday $\mathrm{OH}^{-}$concentration can be estimated to be $3.4 \times 10^{6} \mathrm{molec} \mathrm{cm}^{-3}$. This is in good agreement with estimates calculated using the relationship described by Rohrer and Berresheim (2006). This high value is driven primarily by the high surface albedo. Direct measurements (as opposed to the estimates made here) around the Antarctic region (both continental (Mauldin et al., 2001) and coastal (Bloss et al., 2007; Kukui et al., 2014)) report similarly high $\mathrm{OH}$ concentrations, giving some confidence that our calculations are within realistic ranges.

\subsection{Box modelling}

The nucleation and growth chemistry of the NPF event was investigated using a box model version of the TwOMoment Aerosol Sectional (TOMAS) microphysics algorithm (Adams and Seinfeld, 2002; Pierce and Adams, 2009a, b). Described in detail by Chang et al. (2011), this version of TOMAS is configured to simulate the number and mass of particles by nucleation, condensation and coagulation processes within 44 log-normally spaced size bins spanning dry diameters between $0.5 \mathrm{~nm}$ and $10 \mu \mathrm{m}$. TOMAS currently includes gas-phase sulfur chemistry (dimethyl sulfide (DMS) $\mathrm{SO}_{2}$ and $\mathrm{H}_{2} \mathrm{SO}_{4}$ ) based on work by Chin et al. (1996), which has been shown to work well compared to other schemes in the Arctic (Karl et al., 2007). Given the similar polar environmental conditions, the mechanism should be suitable for the Antarctic environment of this study.

In this environment, the model only considers DMS oxidation as a source of sulfate aerosol. This is reasonable because of the remoteness of the location from other significant sulfate sources, such as volcanoes and anthropogenic activities, which are associated with high $\mathrm{SO}_{2}$ emissions. Numerous publications (e.g. Curran and Jones, 2000; Graf et al., 2010; Shirsat and Graf, 2009, and references therein) also show that the natural DMS emissions are the major sulfur source in the region, with a Southern Ocean flux of $2 \mathrm{Tg} \mathrm{S} \mathrm{yr}^{-1}$ compared to $16 \mathrm{Gg} \mathrm{Syr}^{-1}$ from anthropogenic and volcanic activity in the region. The short lifetime of $\mathrm{SO}_{2}$, at around a day
(Lee et al., 2011), also suggests that transport from these distant sources in sufficient concentrations to contribute significantly to this nucleation event is unlikely and can therefore be ignored.

Recent work has posited the importance of methanesulfonic acid $\left(\mathrm{CH}_{3} \mathrm{SO}_{2} \mathrm{OH}\right.$; MSA) in nucleation and condensational growth processes, particularly in the marine environment (Bzdek et al., 2011; Dall'Osto et al., 2012; Dawson et al., 2012; Bork et al., 2014). A simplified inclusion of MSA into TOMAS was performed such that MSA produced from DMS oxidation was identified as $\mathrm{H}_{2} \mathrm{SO}_{4}$ in the model, and added to the condensing $\mathrm{H}_{2} \mathrm{SO}_{4}$ reservoir, essentially increasing the nucleation and condensational growth rates. This is a reasonable parameterisation for an upper bound of the effects of MSA. The growth of particles larger than $3 \mathrm{~nm}$ by MSA should be equivalent to $\mathrm{H}_{2} \mathrm{SO}_{4}$ as both are essentially non-volatile when condensing to particles of this size (Davis et al., 1998). This simple parameterisation is sufficient for the aims of this study and a full parameterisation of MSA nucleation and growth mechanisms should be performed as part of future work. Consequently, the sensitivity of the model to included MSA parameterisations was not quantified. However, results from this inclusion, although increasing growth rates, did not change the overall conclusions associated with these modelling results.

Two different nucleation mechanisms are available in the TOMAS model that were utilised for this study. The first, known as the empirical mechanism, is a simple activation nucleation parameterisation to predict nucleation rates such that $J_{\text {nuc }}=A\left[\mathrm{H}_{2} \mathrm{SO}_{4}\right]$, where $J_{\text {nuc }}$ is the nucleation rate and $A$ is an empirical parameter (Sihto et al., 2006). This linear dependence is based on the theory that stable, but sub-critical clusters exist that require the addition of a single sulfuric acid molecule to reach critical size where stable condensational growth can occur. This mechanism, although simplified, allows for easy scaling of nucleation rates. The second mechanism calculates rates and critical cluster properties using the ion-mediated nucleation mechanism (Yu and Turco, 2000; $\mathrm{Yu}, 2006,2010)$. This mechanism presumes that charged molecular clusters condense around natural air ions, resulting in nucleation and growth rates significantly faster than neutral counterparts, and can produce nucleation in situations where traditional nucleation mechanisms are unfavourable. Other sulfuric-acid-based schemes (e.g. binary or kinetic nucleation) were not tested because they either produce similar (kinetic) or smaller (binary) nucleation rates than the ones tested here (Yu et al., 2010). Although the model employed does not explicitly simulate schemes of sulfuric acid with ammonia, amines or organics, development to include these schemes was not deemed necessary for this study because of the low concentrations that are likely in the East Antarctic sea ice region where we were far from the region's biggest (although still small in the global context) sources of biological activity (see below) and the continent (e.g. Legrand 
et al., 1998; Davison et al., 1996; Ayers and Gras, 1980; Gras, 1983).

A range of typical input variables to the TOMAS box model, shown in Table 1, was used to account for uncertainties in the nucleation rate. The model was initialised with a pre-existing aerosol size distribution (single or dual mode distributions with variable modal median diameter and number concentration, with a fixed width, $\sigma$, of two, which is unitless in log-normal space) and concentrations of DMS and $\mathrm{OH}^{\cdot}$ that spanned the possible values in the field. Simulations were performed with A factors ranging from $10^{-10}$, suitable for clean polar environments, to $10^{-6}$, those found to suit continental locations (Chang et al., 2011). The preexisting aerosol is assumed to have the density and hygroscopic growth properties of ammonium bisulfate - an assumption with minimal effect compared to changes in size distribution (Chang et al., 2011). The box presumes a pulse of DMS emission, followed by zero emissions - a parameterisation that the movement of the air mass over a significant marine DMS source, followed by a region with zero or low emissions (Chang et al., 2011). Initial concentrations of MSA, $\mathrm{SO}_{2}$ and $\mathrm{H}_{2} \mathrm{SO}_{4}$ are assumed to be zero, and MSA and $\mathrm{H}_{2} \mathrm{SO}_{4}$ are the only included condensable vapours (i.e. no species such as organics) and are assumed to have the same condensable properties. Three estimates of MSA fraction produced from DMS oxidation were used (including 0.1, 0.3 and 0.5 ) that were based on MSA : non-sea-salt sulfate ratios found in the literature, the highest of which represents the upper extreme of reported ratios (e.g. Chen et al., 2012; Legrand et al., 1998; Mauldin et al., 2001, 2004). OH· was kept constant throughout the simulation, with concentrations chosen to span likely values, as well as extremes for model validation. Cloud cycling is not accounted for in the model. Simulations were run for $24 \mathrm{~h}$, which spans more than the total time a constant air mass was present over the measurement site. Over 1000 simulations were run, including all permutations of model inputs, inclusion of MSA condensation and the two nucleation mechanisms.

\section{Results}

The NPF event will be investigated in this paper in the following manner. Trends in aerosol data are first described to give a general overview. After determining the air mass influences throughout the period, the formation and growth rates, as well as the loss mechanisms and rates, are determined. The chemistry of nucleation is then investigated. This is performed first by investigating correlations of aerosol data with photochemical indicators, after which the chemistry is assessed to determine whether known mechanisms can explain observations.

Figure 2 shows a time series of aerosol parameters $\mathrm{CN}_{3-10}, \mathrm{CN}_{10}$, and the $\mathrm{CN}_{3-10} / \mathrm{CN}_{10}$ ratio for a week of the voyage encompassing the NPF event on the 18 Octo-

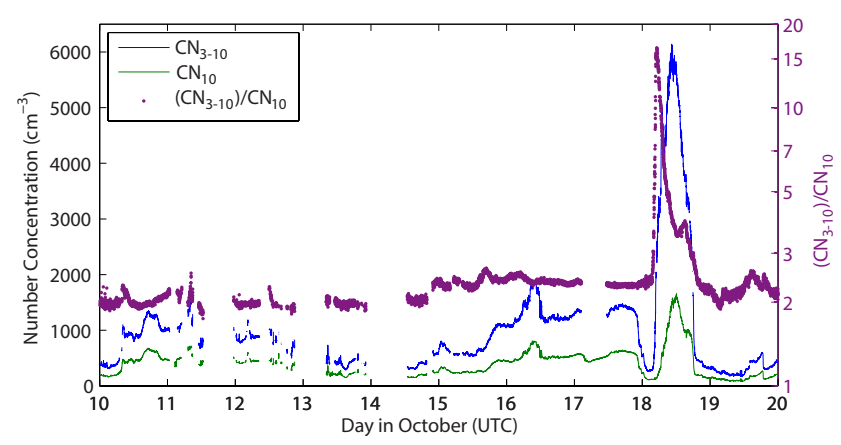

Figure 2. Time series of aerosol parameters for a 10-day subset of the 2012 SIPEXII voyage. Aerosol parameters include calibrated number concentrations of $\mathrm{CN}_{3-10}$ (blue), $\mathrm{CN}_{10}$ (green) and the ratio $\mathrm{CN}_{3-10} / \mathrm{CN}_{10}$ (red). The ratio has been shown previously (Warren and Seinfeld, 1985) to be a good indicator of new particle production when limited measurements are available.

ber 2012. Particle concentrations on this day are observed to be significantly higher than the background concentrations experienced throughout the remainder of the voyage. Background $\mathrm{CN}_{3}$ concentrations had a maximum of $2800 \mathrm{~cm}^{-3}$ (median and mean of 767 and $939 \mathrm{~cm}^{-3}$, respectively) and a ratio value that varies minimally around two (described further in Humphries et al., 2015). The particle formation event on the 18 October was the only one during the full 32-day measurement period that showed both rapid increases in particle concentrations $\left(>1000 \mathrm{~cm}^{-3} \mathrm{~h}^{-1}\right.$ ) beyond background values and evidence of growth. One other high-concentration period was observed but due to the absence of growth indicators, as well as back-trajectory analyses, this was attributed to variations in the age of air masses, which supply background aerosol concentrations to the region. The ratio $\mathrm{CN}_{3-10} / \mathrm{CN}_{10}$ showed very little variation throughout the record (reaching a maximum, not shown, of 4.8 at any other time), but increased by almost an order of magnitude near the start of the event to a maximum of over 16.4 , decreasing as particles grew to diameters larger than $10 \mathrm{~nm}$. This corroborated the attribution of the event as in situ formation rather than fluctuations in background populations.

A more detailed view of the formation event is plotted in Fig. 3. At the peak of the event, $\mathrm{CN}_{3-10}$ number concentrations reached above $6100 \mathrm{~cm}^{-3}$ within a few hours, while $\mathrm{CN}_{10}$ concentrations reached above $1600 \mathrm{~cm}^{-3}$ $\left(\mathrm{CN}_{3} \approx 7700 \mathrm{~cm}^{-3}\right)$. A breakdown of the event is given as follows, with numbering referenced in Fig. 3. An air-mass change, at the beginning of period I, resulted in $\mathrm{CN}_{3}$ number concentrations dropping from $\sim 2000$ to $390 \mathrm{~cm}^{-3}$ just prior to the event, well below average. After an overcast morning, clouds cleared at II, providing the highest levels of solar radiation observed throughout the 32-day measurement period. At III, number concentrations of $\mathrm{CN}_{3-10}$ began to increase rapidly, with no simultaneous increase in $\mathrm{CN}_{10}$ (remaining at background values of $120 \mathrm{~cm}^{-3}$ ), suggesting 


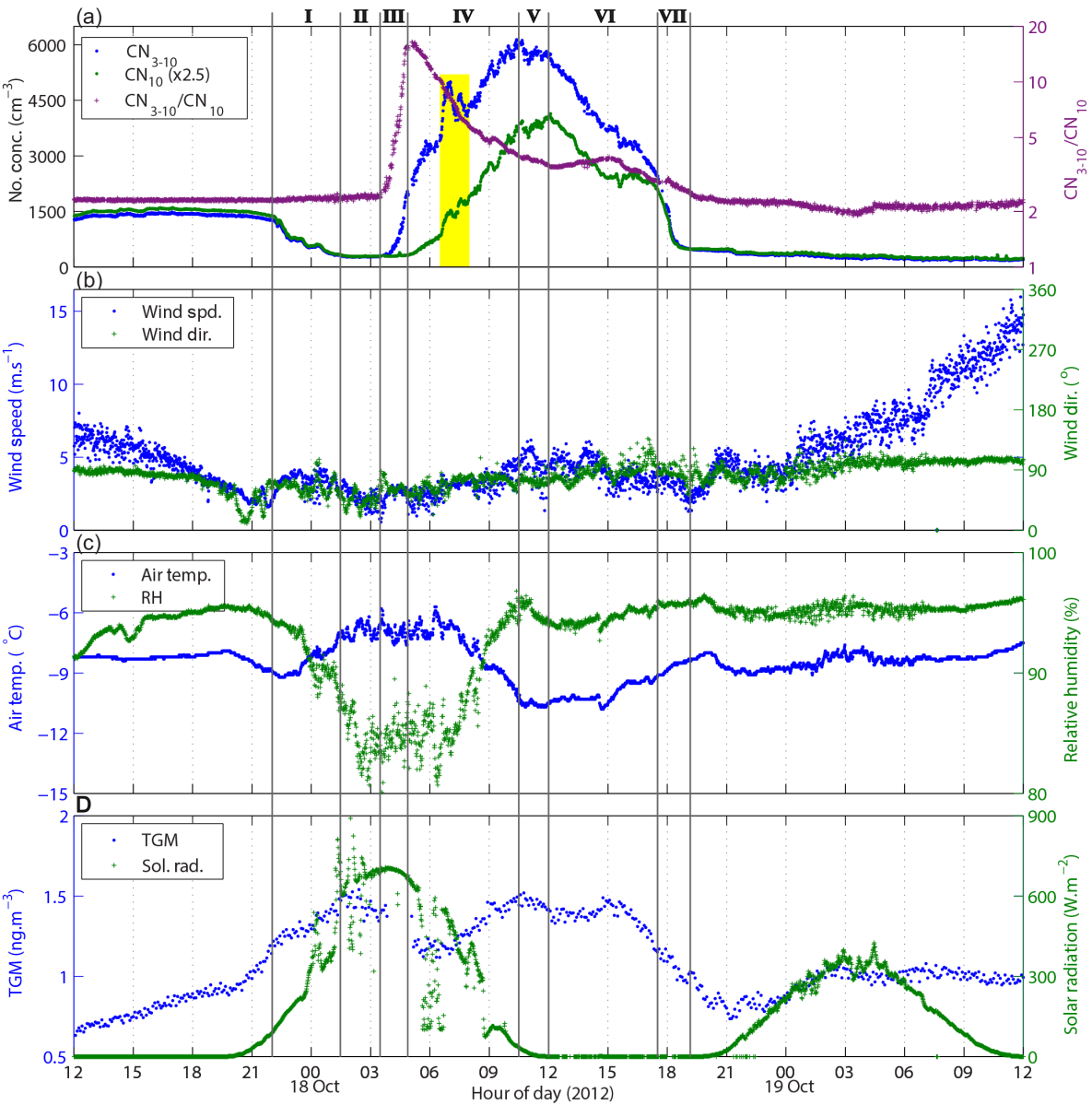

Figure 3. Detailed view of particle formation event along with selected meteorological parameters and TGM concentrations. See text for details of numbered events. (a) Number concentrations of $\mathrm{CN}_{3-10}, \mathrm{CN}_{10}$, and $\left(\mathrm{CN}_{3}-\mathrm{CN}_{10}\right) / \mathrm{CN}_{10}$ show the structure of the formation event clearly. Note the delay between increases in the two size bins, and the linearity of the increase in ratio during period III. The highlighted period shows short-term spikes in both aerosol size bins, with no signal in the ratio data, suggesting this is a result of variations in background concentrations. (b) In situ wind direction during the period is constantly from the east, with minimal variation. Wind speed was low throughout the formation event, remaining below $7 \mathrm{~m} \mathrm{~s}^{-1}$. This is in contrast to the days before and after the event where high wind speeds were observed. (c) The beginning of the event saw slight increases in temperature simultaneous with a $10 \%$ decrease in relative humidity. (d) Solar radiation was found to reach higher levels than any other during the voyage, and decreases in TGM were found to correspond with the period of highest solar radiation.

Table 1. Range of model input parameters to test sulfur chemistry.

\begin{tabular}{ll}
\hline Parameter & Tested values \\
\hline Background aerosol concentration $\left(\mathrm{cm}^{-3}\right)$ & $100,200,400,500,600,1000$ \\
Background Mode Size $(\mathrm{nm})$ & $0.5,1,1.5,2,3,10,30,50,100,150,300$ \\
{$[\mathrm{OH}]\left(\mathrm{molec}^{-3}\right)$} & $2 \times 10^{5}, 4 \times 10^{5}, 5 \times 10^{5}, 6 \times 10^{5}, 8 \times 10^{5}, 1 \times 10^{6}, 5 \times 10^{6}, 1 \times 10^{7}$ \\
Initial $[\mathrm{DMS}](\mathrm{pptv})$ & $100,200,300,400,500,600,700,800$ \\
$\mathrm{~A}\left(\mathrm{~s}^{-1}\right)$ & $10^{-10}, 10^{-9}, 10^{-8}, 10^{-7}, 10^{-6}$ \\
\hline
\end{tabular}

nucleation. About $1.25 \mathrm{~h}$ later, period IV began with growth into the $\mathrm{CN}_{10}$ size range, increasing their number concentrations and simultaneously decreasing the rate of increase of $\mathrm{CN}_{3-10}$. Further increases in $\mathrm{CN}_{3}$ number concentrations ceased at the beginning of period $\mathrm{V}$, likely the result of nu- cleation rates slowing (due to decreased solar radiation) to the same rate as growth into the $\mathrm{CN}_{10}$ size bin (observed from the continued increase in $\mathrm{CN}_{10}$ during period V). At the beginning of VI, particle concentrations in both size bins began to decrease (likely the result of coagulation together 
with reduced nucleation) coincident with zero solar radiation. The rate of decline significantly increased during period VII due to an air-mass change (determined below), ending in background concentrations approximately $8 \mathrm{~h}$ after nucleation ceased. Variability in number concentrations, in particular the highlighted peaks, are suggested to be fluctuations in background concentration due to their simultaneous variation in both size bins and their subsequent absence in ratio data.

\subsection{Identifying a single air mass}

To understand the changes in aerosol data, the various influences on the air mass must be characterised to determine possible sources, sinks and other changes. This was done by consideration of sea ice conditions, measured in situ meteorology, calculated back trajectories, and ancillary composition data such as $\mathrm{O}_{3}$ and TGM.

During the days surrounding the formation event, the ship was stuck, drifting with the pack ice due to weather patterns that caused convergence of the ice floes. This resulted in a lead-free region that was determined by helicopter survey to stretch for at least $20 \mathrm{~km}$ in every direction. This expanse of homogeneous, low profile (and generally multimetre thick) sea ice suggests minimal source contributions from the (ice or ocean) surface since fluxes through the ice are low (e.g. Nomura et al., 2010) and open ocean leads were rare or non-existent.

A selection of meteorological data is included in Fig. 3. Just prior to the event, relative humidity $(\mathrm{RH})$ decreased from around 96 to $85 \%$, while air temperature increased slightly from -8 to $-7^{\circ} \mathrm{C}$, with a $2{ }^{\circ} \mathrm{C}$ variance around the higher temperature. This pattern of decreased RH and slightly increased temperature is consistent with other measurements of NPF in the MBL (Covert et al., 1992). Although wind direction was consistently from the east in the days preceding, during and after the event, changes in RH and air temperature began simultaneously with the drop in aerosol number concentrations, suggesting a change in air mass. Wind speed was below $7 \mathrm{~m} \mathrm{~s}^{-1}$ throughout the event, with high wind speeds up to $20 \mathrm{~m} \mathrm{~s}^{-1} 24 \mathrm{~h}$ both before the event, consistent with the passage of a low pressure system $(967 \mathrm{hPa})$, and after, corresponding to the passage of a high-pressure ridge $(1000 \mathrm{hPa})$. Although these calm conditions could suggest ship emissions were being sampled, the lack of anthropogenic signatures in other data (e.g. $\mathrm{O}_{3}$ or high-frequency particle concentration fluctuations) indicated background air was measured. Other measurements (Raes, 1995; Clarke et al., 1998) found similar low wind speed conditions were necessary for nucleation in the MBL due to lower pre-existing aerosol surface area because of reduced wind-induced sea-spray aerosol. Seaspray aerosol is unlikely to be as important in the sea ice region because of reduced exposed ocean; however, aerosols from blowing snow (Yang et al., 2008) and frost flowers (Rankin et al., 2002) could occur in higher winds. These aerosols would scavenge vapours and prevent nucleation, making the low wind speed similarly important for low preexisting aerosol numbers in this environment.

Trajectories are a useful tool for analysis of air-mass influences; however, at the high latitudes of the Southern Ocean and Antarctic regions, the meteorological data sets on which trajectories are calculated rely on sparse measurements. Consequently, the trajectories calculated in these regions contain high uncertainties and interpretation of these results must be taken with a grain of salt, even if changes in trajectories coincide well with other in situ data. Keeping this in mind, trajectories were calculated for the event day to assess changes in air mass that could have influenced the aerosol event.

Figure 4 shows back trajectories terminating at $10 \mathrm{~m}$ above mean sea level for the period spanning the formation event. Although in situ wind direction was consistently from the east during this period, $72 \mathrm{~h}$ trajectories show significant changes in air-mass history. During the high-aerosol concentrations prior to the event, easterly winds brought air that had been in the free troposphere only $36 \mathrm{~h}$ prior to measurement that was representative of background populations (Humphries et al., 2015). The air-mass change, identified as period I of Fig. 3 and the first red track of Fig. 4a, shows the first signs of air changing direction within the $12 \mathrm{~h}$ prior to the event. The lower aerosol concentrations just prior to the event were found to correspond to air masses that had recently come from the region north-west of the measurement location. During the period of increasing CN (Fig. 4b), trajectories were found to "recirculate" around this northwest region for about $24 \mathrm{~h}$, before being measured. This gives a meso-scale $(\sim 500 \mathrm{~km})$ spatial bound to the chemistry and conditions leading to the formation event, rather than the local scale. A change from this recirculation occurs at approximately 15:00 (UTC; Fig. 4c), when the decreasing aerosol concentrations began to plateau before a sudden decrease, coinciding with an abrupt change in air-mass history that increased influence from areas further west of the recirculation region. Overall, trajectories support the conclusion that a single air mass influenced the measurement location throughout the period of interest, and that this air mass came from the north-west.

Independent measurements of atmospheric components, such as $\mathrm{O}_{3}$, can help in identifying air-mass influence. In Fig. $5 \mathrm{a}, \mathrm{O}_{3}$ can be seen to be relatively constant throughout the nucleation period at approximately $27.5 \mathrm{ppb}$, with abrupt changes occurring at times previously identified (via $\mathrm{CN}$ and trajectory data) as air-mass changes. The constant $\mathrm{O}_{3}$ concentrations between these abrupt changes then, are reflective of the influence of a single air mass.

TGM is another independently measured atmospheric component that shows (Fig. 5a) significant and simultaneous change with the air-mass changes identified previously. Notwithstanding the recent establishment of a number of continuous monitoring stations, background TGM concentrations are still relatively rare in the Southern Hemi- 

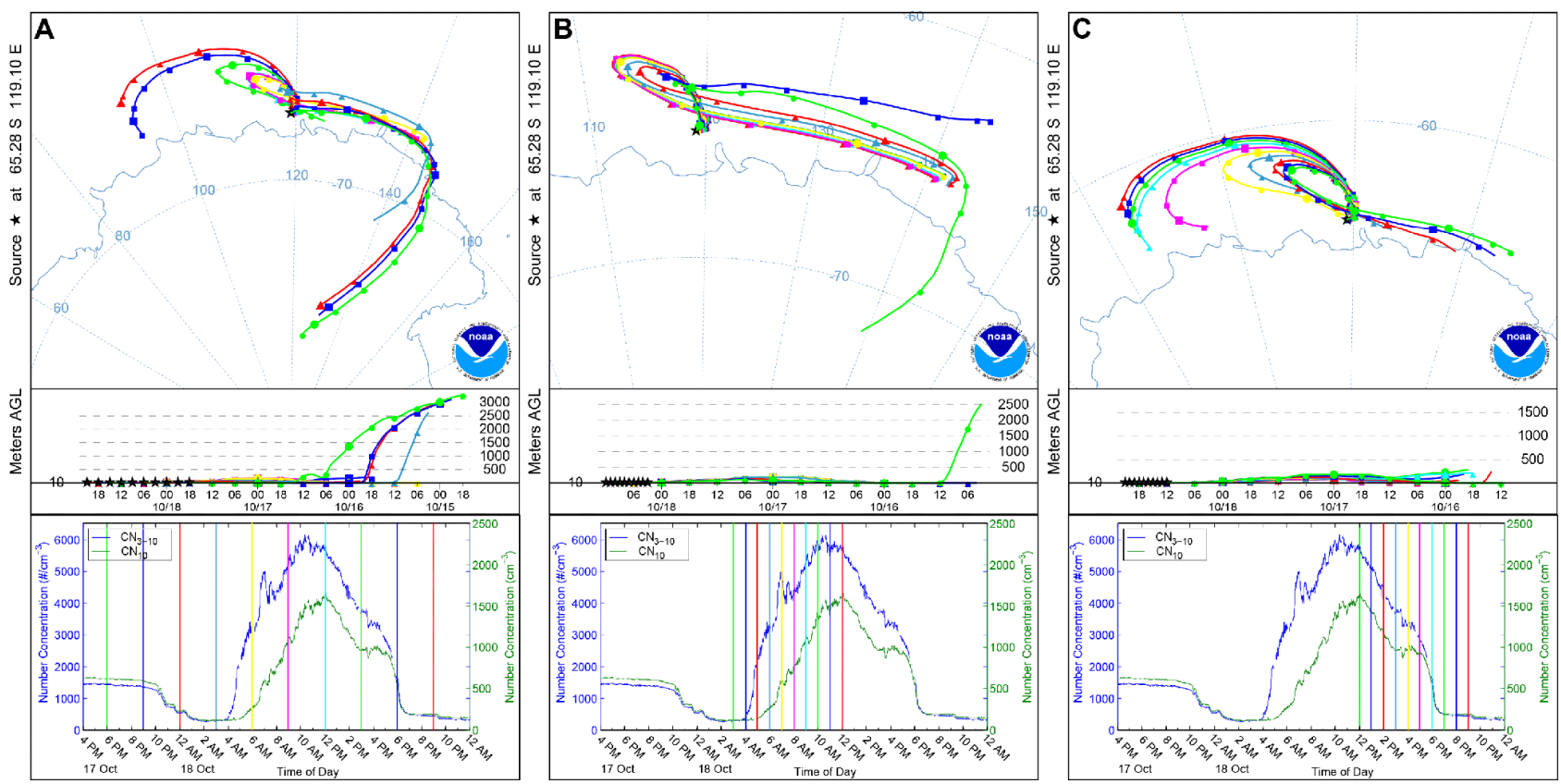

Figure 4. Back trajectories released from $10 \mathrm{~m}$ (a.s.1.) calculated using NOAA's HYSPLIT model and driven by GDAS meteorological data, run for $72 \mathrm{~h}$ during the 18 October particle formation event. Coloured lines in the lower plots show the release time of the trajectory relative to the particle concentration. (a) Ten trajectories, one released every $3 \mathrm{~h}$ between 17 October 18:00 and 18 October 21:00, show the air-mass change from a south-east background, to a more local influence, then back to background from the west. (b) Released hourly and spanning the increase in particle number concentration, between 03:00 and 12:00 18 October, trajectories show that air masses recirculate to the north-west of the ship after travelling along the sea ice surface. (c) Hourly trajectories during the decrease in particle number concentration, between 12:00 and 21:00 18 October, show the local impact steadily being diluted as influence from further west increases. The fastest drop in aerosol concentration is found to occur when recirculation ceases and westerly influence dominates.

sphere (Slemr et al., 2015). Despite short-term spikes above $1.5 \mathrm{ng} \mathrm{m}^{-3}$, our measurements generally showed background values ranging from 0.7 to $1.1 \mathrm{ng} \mathrm{m}^{-3}$ (see Appendix Fig. A2), similar to the most recent southern hemispheric values that range between about 0.8 and $1.1 \mathrm{ng} \mathrm{m}^{-3}$ (Slemr et al., 2011, 2015). During the period being discussed, concentrations increased from less than $1.0 \mathrm{ng} \mathrm{m}^{-3}$, up to $1.5 \mathrm{ng} \mathrm{m}^{-3}$, remaining at this concentration for a sustained period relative to previous spikes, before returning back to background values less than $1 \mathrm{ng} \mathrm{m}^{-3}$, coincident with the ending air-mass change. This corroborates the previous inference of a single air mass identified to be influencing the event.

If nucleation is occurring at the meso-scale, steady or slowly changing aerosol trends will be observed in particle concentration. Conversely, if events are occurring over the scale of tens of metres, sudden and large fluctuations in number concentration would be expected on short timescales on the order of seconds to minutes. The generally steady trends in aerosol number concentrations during this event support the conclusion of a meso-scale homogeneous air mass.

Since a single air mass is influencing the measurement site, it can be concluded that the physics and chemistry over this meso-scale are homogeneous. Consequently, during this NPF event, conclusions about the growth of aerosols and changes in atmospheric composition from measurements from our stationary site can be made confidently (assuming horizontal homogeneity) without worrying that variability is a result of advective effects due to changing air mass.

\subsection{Formation and growth rates}

Formation rates of $3 \mathrm{~nm}$ particles, $J_{3}$, averaged over a given time interval, were calculated using the method described by Kulmala et al. (2004). Assuming the effects of coagulation and transport were small during the chosen time period, a reasonable assumption when air masses are relatively clean and homogeneous, as found in this study, values of $J_{3}$ were found to range from 0.2 to $1.1 \pm 0.1 \mathrm{~cm}^{-3} \mathrm{~s}^{-1}$ depending on the period used for calculation (periods selected for calculation range between $15 \mathrm{~min}$ to $2 \mathrm{~h}$ when the rate of increase in particles was approximately constant). These values compare well with others measured in both the Antarctic region (Davison et al., 1996; Koponen et al., 2003; Asmi et al., 2010; Järvinen et al., 2013) and in various continental mid-latitude locations, which range from 0.001 to $10 \mathrm{~cm}^{-3} \mathrm{~s}^{-1}$ but can reach into the tens of thousands (see review by Kulmala et al., 2004). 


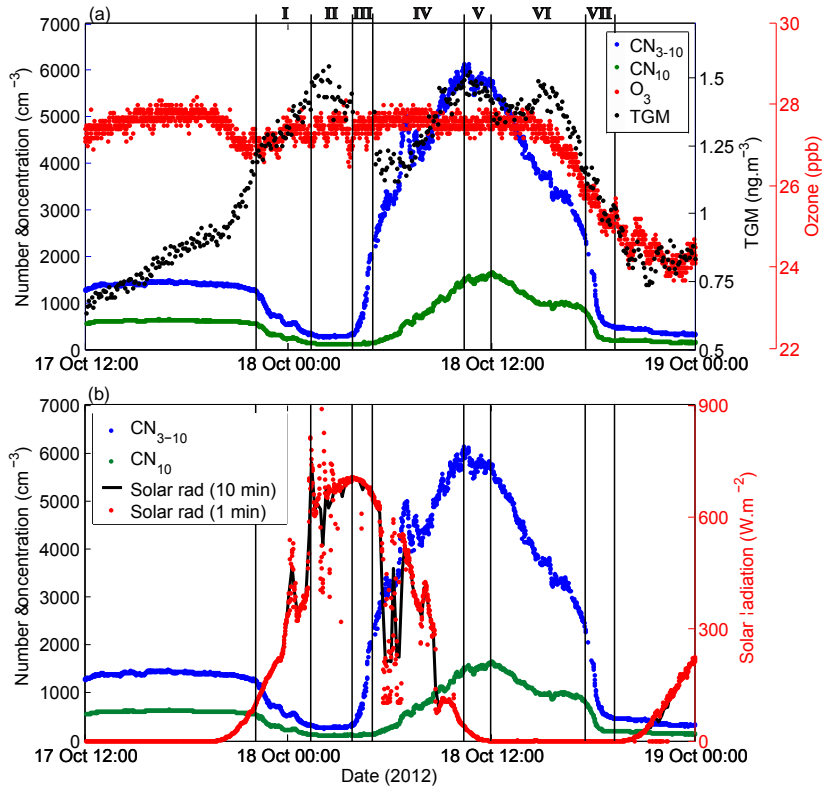

Figure 5. Close up time series showing how various other parameters vary relative to the particle formation event. Aerosol concentrations are included for reference. (a) $\mathrm{O}_{3}$ and TGM. (b) Solar radiation (1 and $10 \mathrm{~min}$ averages).

Aerosol growth is clearly observed in the data set as a delay in increasing number concentrations between the two measured size bins. Quantifying this growth with the available data is difficult and requires careful selection of the data and an assumption that during the period chosen, increases in number concentrations are caused by the nucleation event, and not fluctuations in the background aerosol. The $1.25 \mathrm{~h}$ chosen period (III of Fig. 3) was determined by the constant increase in the $\mathrm{CN}_{3-10} / \mathrm{CN}_{10}$ ratio, and is identified as the clearest period from which growth can be determined to be linear between 3 and $10 \mathrm{~nm}$. The resulting growth rate was $5.6 \pm 0.9 \mathrm{~nm} \mathrm{~h}^{-1}$, similar in magnitude to recent results of new particle formation from continental biogenic precursors (Kyrö et al., 2013), yet 2-6 times larger than those observed at other Antarctic locations (Gras, 1993; Koponen et al., 2003; Park et al., 2004; Asmi et al., 2010; Belosi et al., 2012; Järvinen et al., 2013) and comparable to observations at other mid-latitude coastal locations (O'Dowd et al., 1998, 1999, 2002a; Kulmala et al., 2004).

\subsection{Loss processes}

The decline of $\mathrm{CN}$ to background concentrations at the end of the event is worth detailed consideration for a full understanding of the event. Although trajectories and ancillary data show that the final decline of $\mathrm{CN}$ to background (period VII) is a result of an air-mass change, the gradual decline preceding this (period VI) is likely to be driven by other loss mechanisms. This period is part of the time when a single homo- geneous air mass is influencing the measurement location, as discussed above. Consequently, in situ processes, such as coagulation, are more likely to be driving the declining number concentrations than other processes determined by air-mass changes, such as horizontal dispersion and advection.

The influence of vertical mixing and coagulation can be modelled assuming a well-mixed boundary layer capped with an inversion where particle-free air is being entrained from the free troposphere. This can be quantified by the following equation (Davison et al., 1996), which describes the time rate of change of $\mathrm{CN}$ concentration:

$\frac{\mathrm{d} n}{\mathrm{~d} t}=-n\left(\frac{k n}{2}+\frac{v_{\mathrm{d}}}{H}\right)$,

where $n$ is the total $\mathrm{CN}$ concentration, $t$ is time, $k$ is the coagulation coefficient, $v_{\mathrm{d}}$ is the entrainment velocity and $H$ is the boundary layer mixing height. Integration yields a function dependent only on $k, v_{\mathrm{d}}, H$ and $n_{0}$, the initial concentration, such that

$n=\frac{a c e^{-b t}}{1-c e^{-b t}}$,

where $b=v_{\mathrm{d}} / H, a=2 b / k$ and $c=n_{0} /\left(a+n_{0}\right)$. Taking an entrainment velocity $\left(v_{\mathrm{d}}\right)$ of $0.34 \mathrm{~cm} \mathrm{~s}^{-1}$ (from calculations performed with Weddell Sea measurements by Davison et al., 1996), a calculated boundary layer height $(H)$ of $200 \mathrm{~m}$ (based on trajectories calculated with the UK Met Office's Numerical Atmospheric-dispersion Modelling Environment; Schofield et al., 2014a) and an initial CN concentration of $7500 \mathrm{~cm}^{-3}$, a coagulation coefficient $(k)$ of $(8 \pm 2) \times 10^{-9} \mathrm{~cm}^{-3} \mathrm{~s}^{-1}$ results in the best fit to period VI of the data, shown in Fig. 6. The two variables $v_{\mathrm{d}}$ and $H$, are assumed from the literature and need an assessment of sensitivity. Calculation of $k$ is insensitive to boundary layer height, but highly sensitive to entrainment velocity. Reducing the entrainment velocity by a factor of 10 increases $k$ by only a factor of 2 and results in a similarly good fit. However, an increase in the entrainment velocity by an order of magnitude results in the inability to find a value of $k$ that fits the measurements, a fact consistent with the unrealistic nature of this change. Although the uncertainty around the entrainment velocity parameter is high, it is still possible to conclude that coagulation and vertical mixing are sufficient to explain the loss.

The reduction of $\mathrm{CN}$ concentrations during the event is therefore likely to be explained by three periods. The first, period $\mathrm{V}$, involves very slow loss during which photochemical production of $\mathrm{CN}$ is still possible before sunset. During this period, coagulation has already started but $\mathrm{CN}$ concentrations are being maintained by continued production. At sunset, production ceases and coagulation dominates the changing concentrations of period VI. Later, CN losses increase drastically during period VII, coinciding with the airmass change described previously and shown in Fig. 4c. 


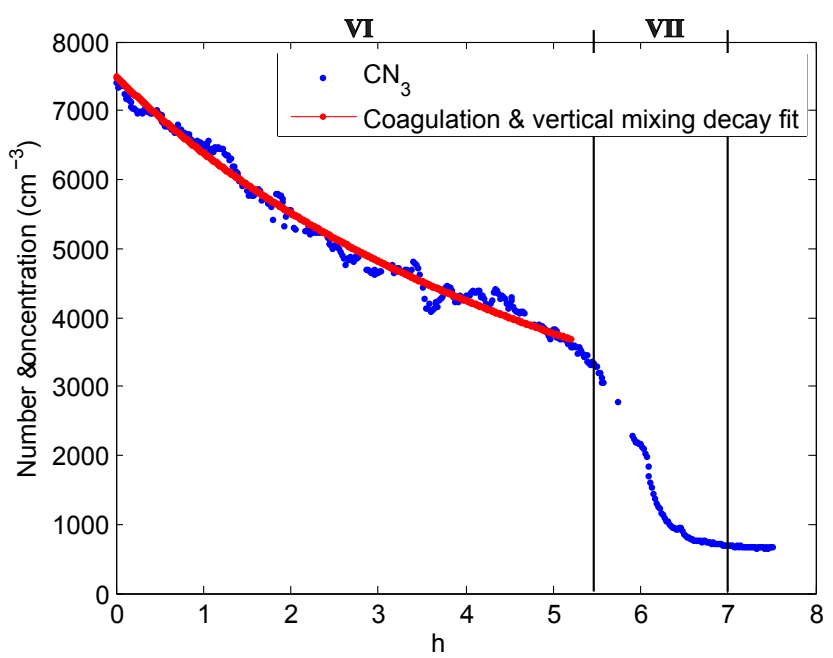

Figure 6. $\mathrm{CN}_{3}$ data with the coagulation and vertical mixing decay fit that is found to fit for the first $5 \mathrm{~h}$ of decay, before an air-mass change results in rapid decay to background at around $5.5 \mathrm{~h}$. Zero hours corresponds to midday on the 18 October (UTC).

Comparison of this coagulation coefficient $((8 \pm 2) \times$ $\left.10^{-9} \mathrm{~cm}^{-3} \mathrm{~s}^{-1}\right)$, derived during period VI, to those of coefficients calculated using Fuchs' formula at $-11^{\circ} \mathrm{C}$ (Seinfeld and Pandis, 2006), yields information about the likely sizes of coagulating aerosols. Fuchs' formula calculates the coagulation coefficient by considering the coagulation of two particles with wet diameters $D_{1}$ and $D_{2}$. Resulting calculations yield coagulation coefficients of $(8 \pm 0.1) \times 10^{-9} \mathrm{~cm}^{-3} \mathrm{~s}^{-1}$, only when a $D_{1} / D_{2}$ ratio of $5.1 \pm 0.3$ exists. Ratio values above 5.5 or below 4.6 correspond to coagulation coefficients well outside the range plausible for a reasonable fit to the data. Particles with the appropriate diameter ratio, for example 3 and $17 \mathrm{~nm}$, or 4 and $21 \mathrm{~nm}$, are therefore the most likely to be present and responsible for the observed coagulation rate.

\subsection{Aerosol surface area}

If existing aerosol concentrations are high enough to provide a sufficient surface area, precursors are more likely to condense onto these surfaces rather than nucleate to form new nuclei. Although aerosol surface area cannot be calculated accurately from the available data, approximate values can be inferred using Antarctic aerosol size distributions from the literature, along with size information revealed from theoretical calculations (above). Assuming a mean background aerosol population diameter of $100 \mathrm{~nm}$, consistent with measurements by Koponen et al. (2002), the air-mass change prior to the event resulted in a transition in pre-existing aerosol surface area from 19 to $4 \mu \mathrm{m}^{2} \mathrm{~cm}^{-3}$. During nucleation, the aerosol population changed drastically, increasing in number, but decreasing in mode size. Using the number concentrations and size information derived from co- agulation calculations, aerosol surface area remained below $5 \mu \mathrm{m}^{2} \mathrm{~cm}^{-3}$ until nucleated particles grow to sizes exceeding $\sim 30 \mathrm{~nm}$ in diameter. Previous studies have suggested that NPF is possible in the MBL only when pre-existing aerosol surface area is below $5-25 \mu^{2} \mathrm{~cm}^{-3}$ (Covert et al., 1992; Raes, 1995; Clarke et al., 1998), suggesting that conditions before and during this event are suitable for precursor nucleation rather than scavenging.

\subsection{Solar radiation and clouds}

This event was characterised by an abnormally high incoming solar radiation (global irradiance), which was a result of exceptionally clear cloud conditions that were uncommon during the cruise (Fig. 3d). Sustained periods of solar radiation reached above $700 \mathrm{~W} \mathrm{~m}^{-2}$ at midday, at least $100 \mathrm{~W} \mathrm{~m}^{-2}$ higher than any other day during the 32-day measurement period. Ship-based web-camera data show that between thick periods of stratocumulus surrounding the event, light cumulus clouds caused short-term $(\sim 10 \mathrm{~min})$ decreases from the clear-sky radiation as well as short-term increases resulting from cloud-edge effects.

Thick stratocumulus cloud began to clear at approximately 01:20 (UTC) and full cloud-free conditions lasted for around $4.5 \mathrm{~h}$, encompassing solar noon. The start of the NPF event, as evidenced by increasing $\mathrm{CN}_{3-10}$, was found to occur approximately $2 \mathrm{~h}$ after the clouds cleared. If the nucleation event was photochemically initiated, this $2 \mathrm{~h}$ period gives an estimate of the time frame required for precursor oxidation, nucleation and subsequent growth up to $3 \mathrm{~nm}$ (the lower size threshold for detection).

Although the rate of increase of $\mathrm{CN}_{3-10}$ reduced when clouds returned towards the end of the day, concentrations continued to rise until around sunset (12:00 UTC). A similar pattern was observed in the $\mathrm{CN}_{10}$ data set, which together suggested photochemically driven nucleation. This relationship may be explained by one of two options: the high levels of solar radiation that may have been necessary for initiation, were no longer required for continued chemistry, or the high levels of radiation produced a reservoir of oxidised species that were slowly depleted throughout the day. Although interesting, determination of this level of detail of the nucleation mechanism is premature and would need additional measurements (e.g. photolysis rates, measurements of $\mathrm{OH}$ ), unavailable during this campaign. A qualitative investigation of reacting species is the more important first step.

\subsection{Nucleating species and mechanisms}

To understand the nucleation chemistry occurring during the day, an assessment of the various known mechanisms is performed to determine the likelihood of each. Where possible, measurements of possible precursors are utilised, and in their absence, modelling studies are employed. 


\subsubsection{Volatile organic chemistry}

Pre-existing aerosol concentrations in the air mass were sufficient $\left(\mathrm{CN}_{3}=280 \mathrm{~cm}^{-3}\right)$ to seed aerosol growth via condensation of volatile organic compounds (VOCs) (Hoffmann et al., 1997), or extremely low volatility organic compounds (ELVOCs; which are able to condense with even lower aerosol concentrations) (Ehn et al., 2014). For this heterogeneous growth to occur, VOC concentrations must be sufficiently high to condense onto pre-existing surfaces. In the MBL, VOC concentrations necessary to form secondary organic aerosol (SOA) are generally only observed during heavy phytoplankton blooms (e.g. Meskhidze and Nenes, 2006). Although a full suite of VOC concentrations were not measured during SIPEXII, proxies for biological activity were. Atmospheric biogenic halogenated compounds, measured using GC-ECD (e.g. $\mathrm{CHBr}_{3}$ ), showed no deviation from baseline in the days encompassing the event. Surface water fluorescence was measured during the voyage, and after conversion to chlorophyll concentration (a proxy for biological activity) could be compared to previous studies relating chlorophyll to SOA formation. Studies by $\mathrm{Hu}$ et al. (2013) showed that chlorophyll concentrations necessary for organic concentrations sufficient for SOA formations are of the order of $10-60 \mathrm{mg} \mathrm{m}^{-3}$, which were a result of summer phytoplankton blooms in Prydz Bay, Antarctica. During SIPEXII, no such phytoplankton blooms were observed, and chlorophyll concentrations reached a maximum of $0.4 \mathrm{mg} \mathrm{m}^{-3}$ (median of $0.15 \mathrm{mg} \mathrm{m}^{-3}$ ) during the aerosol measurement period, with an order of magnitude lower concentrations on the event day, averaging $0.06 \pm$ $0.03(2 \sigma) \mathrm{mg} \mathrm{m}^{-3}$. Chlorophyll $a$ concentrations acquired from the NASA Oceancolor website (http://oceancolor.gsfc. nasa.gov) confirm in situ data, with concentrations well below $0.3 \mathrm{mg} \mathrm{m}^{-3}$ in the hundreds of kilometres surrounding the measurement location. Despite this evidence, nucleating species could be produced in situ. However, the measurements taken aboard SIPEXII strongly indicate that their concentrations, if present, are at a minimum during the event compared to other periods of the voyage, suggesting their involvement is unlikely.

\subsubsection{Halogen chemistry}

Active nucleation chemistry involving iodine oxidation has been demonstrated to occur rapidly on the local scale when coastal kelp beds are exposed during low-tide periods (O'Dowd et al., 1998, 1999, 2002a). This chemistry is found to coincide with high levels of iodine monoxide (IO) of up to $6 \mathrm{pptv}$ (Saiz-Lopez and Plane, 2004). In situ (Frieß et al., 2001, 2010; Saiz-Lopez et al., 2007b; Atkinson et al., 2012) and satellite (Saiz-Lopez et al., 2007a; Schönhardt et al., 2008, 2012) measurements of IO (and $I_{2}$ ) reveal Antarctica as a global iodine hotspot, particularly in the West Antarctic during spring, where concentrations of $6 \mathrm{pptv}$ are fre- quent, and midday values up to 20 pptv have been observed. Although these high concentrations suggest that nucleation from iodine chemistry could be prolific in the Antarctic region in general, measurements during this voyage found IO concentrations average below about $0.5 \mathrm{ppt}$, and during the nucleation event, concentrations were at the detection limit of approximately $0.1 \mathrm{ppt}$. The influence of a single regional air mass, combined with the exceedingly low IO concentrations measured during the event, make it unlikely that iodine chemistry was responsible for this observed nucleation event.

\subsubsection{Sulfur chemistry}

Nucleation mechanisms involving sulfuric acid (e.g. binary nucleation of $\mathrm{H}_{2} \mathrm{SO}_{4}$ and $\mathrm{H}_{2} \mathrm{O}$ ) are the most common in the atmosphere. Because of this ubiquity, these simple mechanisms are often the only ones included in chemistry and climate models. More complex mechanisms involving ternary species, such as ammonia and amines (Korhonen et al., 1999) have been the focus of recent research (Kirkby et al., 2011), but are yet to be incorporated widely in model chemistry. In the Antarctic region, significant sources of these nitrogen compounds occur around penguin rookeries (Legrand et al., 1998). However, calculated air-mass trajectories (presented above) found that influence for this event came from a region consisting only of sea ice. In the 52 days in the sea ice, only small groups (5-50) of transitory penguins were observed in these conditions, suggesting insufficient numbers to provide a significant amine source (Legrand et al. (1998) observed permanent populations in the thousands). Consequently, ternary nucleation mechanisms are unlikely to be important during this event, and have not been incorporated into modelling efforts.

It was not possible to determine whether sulfur chemistry was involved in nucleation using the measurements available in this study. To fill this gap in measurements, the TOMAS box model was employed to examine whether existing binary nucleation schemes involving sulfuric acid could explain the observed nucleation rates. The source of $\mathrm{H}_{2} \mathrm{SO}_{4}$ employed in this box model was the biggest natural sulfur source, DMS. Utilisation of a box model was suitable for this study primarily because of the single homogeneous air mass influencing the measurement location during the event.

The purpose of the modelling study was to determine whether existing $\mathrm{H}_{2} \mathrm{SO}_{4}$-dependent nucleation schemes could account for observations under the measured conditions. If, even under the most favourable conditions for DMSdriven nucleation and growth (high DMS and $\mathrm{OH}$ concentrations), the model cannot produce the observed number and rate of growth, it is likely that another species or alternate chemical mechanism is driving the nucleation chemistry. Because the study aimed for a qualitative result, it was suitable to account for the (potentially high) uncertainty associated with the input variables by using a wide range of both plausible and extreme values, outlined earlier in Table 1. 
Analysis of results determined that no combination of input parameters utilising either nucleation mechanism included in the model could simultaneously produce both the formation and growth rates necessary to explain the observed nucleation event. A summary of the best results is presented in Table 2. It is clear that under all environmentally realistic conditions, formation rates were at the lower limit of observations, while growth rates were a factor of 2 lower than those observed. Inclusion of MSA chemistry into the model increased growth rates significantly (not presented); however, this modification still did not result in any simulations that were able to reproduce observations.

Interestingly, when the background aerosol population was initialised with a single mode with a diameter of less than $3 \mathrm{~nm}$ (simulating seed aerosol), model simulations were able to reproduce the observed rates using a range of input variables (case $d$ in Table 2). However, it was suspected that this result was a consequence of the removal of the accumulation mode background populations, which would usually scavenge much of the condensible material, providing conditions where growth rates at these early stages were unrealistically high. To test realistic conditions, where both a seed population and an accumulation mode background population are present, the initial aerosol population was modified to have a dual mode distribution, with peaks in both the nucleation $(1.5 \mathrm{~nm})$ and accumulation $(100,150$, and $300 \mathrm{~nm})$ modes (case e in Table 2). Reintroduction of this background aerosol load, at a modest number concentration of $120 \mathrm{~cm}^{-3}$ (based on measurements), meant that even when seed populations were present, no set of input parameters could be found that could explain observations.

It could be concluded then that known sulfur chemistry alone, with or without MSA, is insufficient to explain the observed new particle formation event. Since the most common precursors (i.e. organics, halogens and sulfuric acid) are unlikely to be able to explain the nucleation and growth alone, it is likely that an alternative species must be participating in this process.

\subsubsection{Mercury chemistry}

From the investigation discussed above, known nucleation mechanisms involving sulfuric acid, iodine or organics were unable to explain the observed aerosol data, leaving previously unidentified chemistry the likely explanation. No correlations were found with other measured data except for, surprisingly, TGM.

During the particle formation event, TGM was found to exhibit the highest sustained concentration to date in this data set, varying from sustained concentrations of around $1.5 \mathrm{ng} \mathrm{m}^{-3}$. The $4 \mathrm{~h}$ cloud-free period, described above, was found to correspond directly with the full duration of the first decline in TGM concentration (Fig. 5b). The beginning of this decline corresponded directly with the clearing of the major cloud bands, which experienced significantly high peaks of cloud-edge effect radiation. The period of declining TGM ended simultaneously with the appearance of a temporary cloud period around 06:00 (UTC), and did not begin to decline again when this cloud cleared and solar radiation had dropped below $600 \mathrm{~W} \mathrm{~m}^{-2}$. This correlation suggests possible photochemically driven chemistry involving TGM that may require high incoming solar radiation levels - chemistry that is consistent with previous studies that have observed photochemically derived mercury oxidation products in the Arctic atmosphere (Lindberg et al., 2002).

This $4 \mathrm{~h}$ period of declining TGM concentrations, from an initial value of $1.50 \pm 0.05$ down to $1.16 \pm 0.05 \mathrm{ng} \mathrm{m}^{-3}$, represents an atmospheric TGM depletion of about $20 \%$. The decline, along with the $4 \mathrm{~h}$ recovery back to baseline, was most likely caused by in situ chemistry, rather than an airmass change, which has been discounted for this period by previous arguments. As discussed by Lindberg et al. (2002), photochemical reactions producing halogen and $\mathrm{OH}$ radicals are able to react with $\mathrm{Hg}^{0}$ to produce oxidised compounds such as $\mathrm{HgO}, \mathrm{Hg}(\mathrm{OH})_{2}, \mathrm{Hg} X_{2}$ or $\mathrm{Hg} X Y$ (where $X$ and $Y$ are halogens). Additionally, $\mathrm{Hg}(\mathrm{II})$ products are able to be photolytically released directly to the atmosphere from surfaces such as the snowpack (United Nations Environmental Programme, 2008). Oxidation products have properties that make them suitable for nucleation processes, such as being solid at equilibrium under atmospheric conditions making them unlikely to evaporate from nucleating clusters (Schroeder and Munthe, 1998). Production of these species can occur by direct emission or in situ chemistry. Ordinarily, $\mathrm{Hg}$ oxidation products, once produced, are readily scavenged by pre-existing aerosol populations. This interpretation could be largely driven by the location of most $\mathrm{Hg}$ studies being in regions of high pre-existing aerosol surface area. In more pristine conditions where pre-existing aerosol surface area is low, such as those observed in this Antarctic study, these oxidation products have the potential to nucleate rather than adhere to existing surfaces.

To further investigate the possibility of nucleation involving $\mathrm{Hg}$, a lagged correlation was calculated between TGM and $\mathrm{CN}_{3-10}$. Unfortunately, there was insufficient data ( $n=$ 40) for a full mathematical derivation of the lag period that produced the best correlation. The best fit was determined by calculating the linear model iteratively, incrementing the lag time by $5 \mathrm{~min}$ steps (limited by TGM time resolution) and visual assessment. Figure 7 shows the resulting best fit that occurred at a time delay of around $2 \mathrm{~h}$ and yielded a negative correlation with an $R^{2}$ value of 0.74 . If $\mathrm{Hg}$ chemistry was involved in aerosol nucleation, the $2 \mathrm{~h}$ time delay from these calculations puts a time frame on the chemical mechanism from gas phase (either $\mathrm{Hg}^{0}$ or $\mathrm{Hg}$ (II)) to $3 \mathrm{~nm}$ aerosol, consistent with estimates from solar radiation data.

The influence of a single air mass throughout the period suggests that the recovery of TGM after nucleation was the result of a new source rather than an air-mass change. It is well established that $\mathrm{Hg}$ oxidation products can be photolyt- 
Table 2. Formation and growth rates found experimentally (top) and from the model (bottom). For each model case (changes to the number of modes, the inclusion of MSA and the mechanism, where "Emp." refers to the empirical mechanism and "IMN" is ion-mediated nucleation), the parameters and results shown in the table represent the best approximation of observations. Only one case (d) produced values that were representative of observed values; however, this is unrealistic because it represents an environment free from background aerosol, essentially removing precursor scavenging. Parameter values common to all model simulations present include $[\mathrm{OH}]=5 \times 10^{6} \mathrm{molec}^{-3}$ and $A=1 \times 10^{-8} \mathrm{~s}^{-1}$.

\begin{tabular}{|c|c|c|c|c|c|c|c|c|}
\hline Case & No. modes & MSA & Mech. & $\begin{array}{l}\text { Bgnd Conc. } \\
\qquad\left(\mathrm{cm}^{-3}\right)\end{array}$ & $\begin{array}{r}\text { Bgnd mode diam } \\
(\mathrm{nm})\end{array}$ & $\begin{array}{r}\text { [DMS] } \\
(\mathrm{pptv})\end{array}$ & $\begin{array}{l}\text { Formation rate, } J_{3} \\
\qquad\left(\mathrm{~cm}^{-3} \mathrm{~s}^{-1}\right)\end{array}$ & $\begin{array}{l}\text { Growth rate } \\
\qquad\left(\mathrm{nmh}^{-1}\right)\end{array}$ \\
\hline \multicolumn{9}{|c|}{ Model Results } \\
\hline $\mathrm{a}$ & Single & No & Emp. & 500 & 100 & 800 & 0.1 & 2 \\
\hline $\mathrm{b}$ & Single & No & IMN & 100 & 50 & 400 & 3 & 2 \\
\hline $\mathrm{c}$ & Single & Yes & Emp. & 100 & 100 & 800 & 0.4 & 3 \\
\hline d & Single & Yes & Emp. & $100-1000$ & 1.5 & $200-800$ & $0.5-1$ & $3-6$ \\
\hline $\mathrm{e}$ & Dual & Yes & Emp. & 100 & $100 \& 1.5$ & 800 & 0.4 & 3 \\
\hline \multicolumn{9}{|c|}{ Observations } \\
\hline \multirow{4}{*}{\multicolumn{5}{|c|}{$\begin{array}{l}\text { This study } \\
\text { Coastal Antarctica (Koponen e } \\
\text { Mid-latitude MBL* } \\
\text { Mid-latitude rural continental* }\end{array}$}} & & & $0.2-1.1$ & $5.6 \pm 0.9$ \\
\hline & & & & & & & 0.5 & $1-2$ \\
\hline & & & & & & & $<1$ & $<5$ \\
\hline & & & & & & & $0.1-5$ & $0.5-10$ \\
\hline
\end{tabular}

* See review of Kulmala et al. (2004).

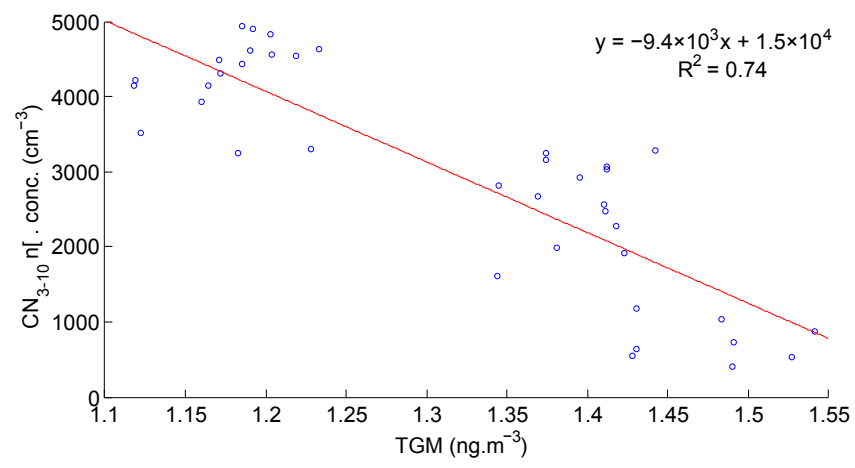

Figure 7. A negative linear correlation is found when $\mathrm{CN}_{3-10}$ was time lagged by $2 \mathrm{~h}$ relative to TGM, suggesting involvement of $\mathrm{Hg}$ in the nucleation chemistry. Data used show a $5 \mathrm{~h}$ period, starting 18 October 02:00 for TGM and 04:00 for $\mathrm{CN}$ data. The data gap surrounding TGM concentrations of $1.3 \mathrm{ng} \mathrm{m}^{-3}$ is a result of routine calibrations, which coincided with the period of interest, and resulted in a 90 min data-gap.

ically reduced back to $\mathrm{Hg}^{0}$ in aqueous environments such as those found in cloud droplets (International Programme on Chemical Safety, 2001; United Nations Environmental Programme, 2008; Feddersen et al., 2012). Aerosol nucleation and growth processes almost invariably require water molecules to adhere to the other condensing species, thereby creating an environment potentially suitable for aqueous chemistry leading to $\mathrm{Hg}^{0}$ emission. Heterogeneous surface chemistry is also possible in these environments, which may lead to similar emission of $\mathrm{Hg}^{0}$ and recovery of TGM con- centrations (Schroeder and Munthe, 1998). As such, the new source that may lead to TGM recovery is likely to be the nucleating aerosol itself. This idea is supported by positive linear correlations between TGM, and $\mathrm{CN}_{3-10}$ and $\mathrm{CN}_{10}\left(R^{2}\right.$ of 0.53 and 0.67 , respectively) during the period between the beginning of TGM recovery and the end of the event, as shown in Fig. 8. Re-emission of $\mathrm{Hg}^{0}$ after its involvement in nucleation means that $\mathrm{Hg}$ species may not be found in elemental analyses of grown particles that may be performed in the future.

These correlations suggest, rather surprisingly, the involvement of mercury in the initial nucleation stages onto which other unidentified species can condense and grow. To determine whether this chemistry is possible, the number of mercury molecules available for nucleation was calculated. A linear regression to the period of TGM decline revealed a rate of decline of $(2.1 \pm 0.2) \times 10^{5}$ molec $\mathrm{cm}^{-3} \mathrm{~h}^{-1}$. Under the reasonable assumption that TGM is primarily $\mathrm{Hg}^{0}$ (Slemr et al., 1985; Schroeder and Jackson, 1987) and a $1: 1$ stoichiometry exists between $\mathrm{Hg}^{0}$ and reactive gaseous mercury products (e.g. $\mathrm{HgO}, \mathrm{HgBr}_{2}$, and $\mathrm{HgCl}_{2}$ ), the full $4 \mathrm{~h}$ depletion period produces a total of $(8.4 \pm 0.2) \times 10^{5} \mathrm{molec} \mathrm{cm}^{-3}$. Assuming all of this contributed to the $5500 \mathrm{~cm}^{-3}$ of aerosol nuclei, each nucleus would have around 150 molecules. Assuming sphericity and that bulk properties are similar to aerosol properties, aerosol diameters using purely TGM molecules range from 2.2 to $2.8 \mathrm{~nm}$ (depending on the chemical identity). This is sufficient for aerosol genesis, provided other condensable species are available for further growth.

Oxidised mercury products are formed regularly in the atmosphere, and are found frequently in atmospheric partic- 

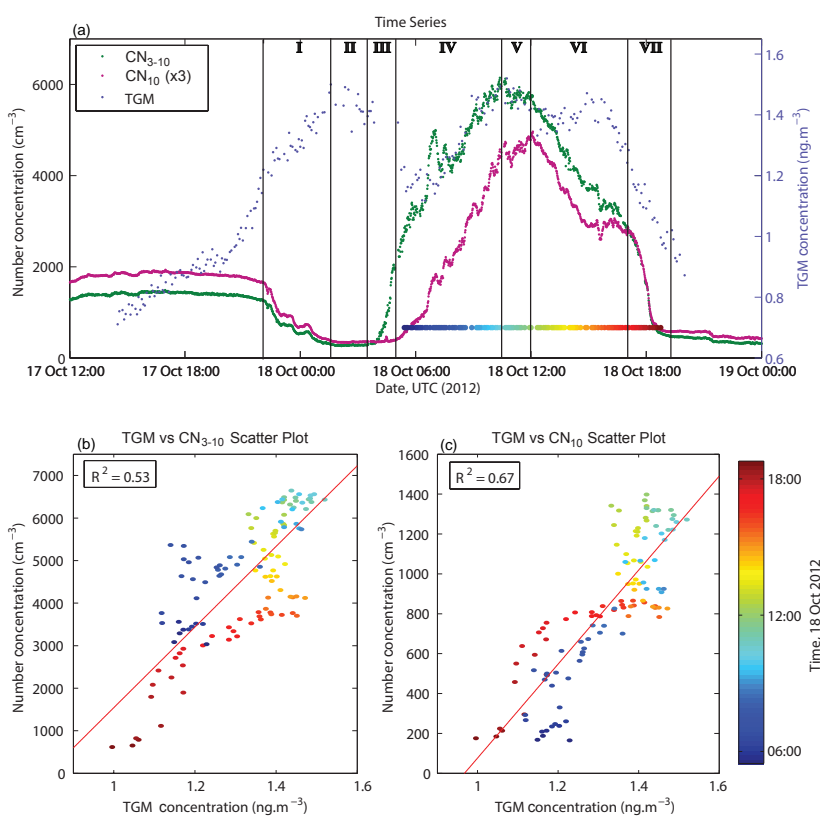

Figure 8. TGM and number concentrations of aerosols in the two measured size bins during the particle formation event. (a) Time series showing variations in concentrations of aerosols and TGM. (b) and (c) show correlation plots relating TGM with $\mathrm{CN}_{3-10}$ and $\mathrm{CN}_{10}$, respectively. Both correlation plots show positive relationships, with deviations occurring primarily because of shortterm variations in aerosol concentrations. The correlation plots are coloured according to time of day (referenced directly in a) and include robust linear regression lines with corresponding $R^{2}$ values. Removal of the "wings" of plot (b), a result of varying background concentrations (see text), increases the $R^{2}$ value to 0.85 .

ulate matter (termed particulate mercury, $\mathrm{Hg}(\mathrm{p})$ ). The processes leading to the formation of $\mathrm{Hg}(\mathrm{p})$ generally involve the oxidation of $\mathrm{Hg}^{0}$ to reactive gaseous mercury compounds $(\mathrm{Hg}(\mathrm{II}))$, which are of sufficiently low vapour pressure that they readily bind to pre-existing aerosol surfaces. This process of oxidation to deposition occurs on the timescale of hours to days (United Nations Environmental Programme, 2008). In the case where pre-existing aerosol concentrations are low, such as those observed in the event being described, we speculate that reactive gaseous mercury may nucleate by itself, or together with other species, to form new aerosol particles.

The day preceding the new particle formation event experienced a significant bromine-driven mercury depletion event (shown in the Appendices), similar to those commonly observed in the Arctic springtime (e.g. Schroeder et al., 1998; Lu et al., 2001; Ebinghaus et al., 2002; Boudries and Bottenheim, 2000; Lindberg et al., 2002) together with high snowfall. The chemistry involved in this mercury depletion results in oxidised mercury species being deposited onto the snowpack surface of the sea ice from which it can enter the hydrosphere and biosphere, or can be reduced to elemental mer- cury and re-emitted back to the atmosphere photolytically (United Nations Environmental Programme, 2013). Given the high solar radiation that influenced the event, it is possible that these reduced mercury compounds were photolytically re-emitted directly from the surface from the previous day's deposition event. These direct emissions (which may or may not undergo further in situ chemical reactions) could be sufficient to explain observations.

It is also possible that $\mathrm{Hg}^{0}$, readily available from longrange transport, is oxidised in situ to $\mathrm{Hg}$ (II) compounds, which then condense to form the new nuclei. $\mathrm{Hg}^{0}$ can be oxidised by numerous species including $\mathrm{O}_{3}$ (Snider et al., 2008), $\mathrm{OH}^{\cdot}$ and halogens (X), producing a range of $\mathrm{Hg}(\mathrm{II})$ compounds suitable for condensation (some listed above).

The identity of the oxidant in this event is worthwhile considering. Steady concentrations of $\mathrm{O}_{3}$ at around $27.5 \mathrm{ppbv}$ (at $1 \mathrm{~atm}$ and $0{ }^{\circ} \mathrm{C} ; 27.5 \mathrm{ppbv} \approx 7.5 \times 10^{11} \mathrm{molec} \mathrm{cm}^{-3}$ ) throughout the period suggest it is not involved, and its slow reaction rate relative to other reactions makes it unlikely to have occurred (Hynes et al., 2009). OH concentrations on the 18 October were calculated to be high, likely due to a combination of enhanced solar radiation levels and high surface albedo, at $3.4 \times 10^{6}$ molec $\mathrm{cm}^{-3}$, although the slow rate constant of $(10.1 \pm 1.3) \times 10^{-14} \mathrm{~cm}^{3} \mathrm{molec}^{-1} \mathrm{~s}^{-1}$ (at event temperature of $266 \mathrm{~K})$ (Pal and Ariya, 2004), and thermodynamic data (Calvert and Lindberg, 2005; Dibble et al., 2012) suggest it is insufficient to fully explain nucleation. Discussed in detail in the Appendices, an assessment of measurements and the literature suggests that although the reaction rates of $\mathrm{Hg}$ with iodine and chlorine radicals are high (rate constant for $\mathrm{Cl}$ is $(1.0 \pm 0.2) \times 10^{-11} \mathrm{~cm}^{3} \mathrm{molec}^{-1} \mathrm{~s}^{-1}$; Ariya et al., 2002; Stephens et al., 2012), their concentrations are too low to be likely oxidants for this event. Although bromine is observed at low concentrations relative to other periods, it could be present in sufficient concentrations such that when combined with its fast rate constant $\left((3.2 \pm 0.3) \times 10^{-12} \mathrm{~cm}^{3}\right.$ molec $^{-1} \mathrm{~s}^{-1}$; Ariya et al., 2002; Stephens et al., 2012) it could be a prime candidate for the oxidant of this event; however, evidence is still limited to make a firm conclusion here.

Whatever the mechanism of production or identity of the oxidant, oxidised mercury species have the potential to condense, either homogeneously or on pre-existing sub-critical nuclei, to form critical nuclei from which rapid growth can occur via condensation of other species (or other oxidised $\mathrm{Hg}$ compounds). It is possible then, that $\mathrm{Hg}$ was necessary for aerosol nucleation in this event where background aerosol surface area was sufficiently low. A possible nucleation pathway, driven by $\mathrm{Hg}$, is outlined in Fig. 9. Importantly, the oxidised $\mathrm{Hg}$ resulting from this reaction mechanism may be recycled back to TGM (given the trends and relationship presented in Fig. 8), resulting in no net effect on the mercury budget. Although this mechanism is theoretically possible, Hg-driven aerosol nucleation has not been previously de- 


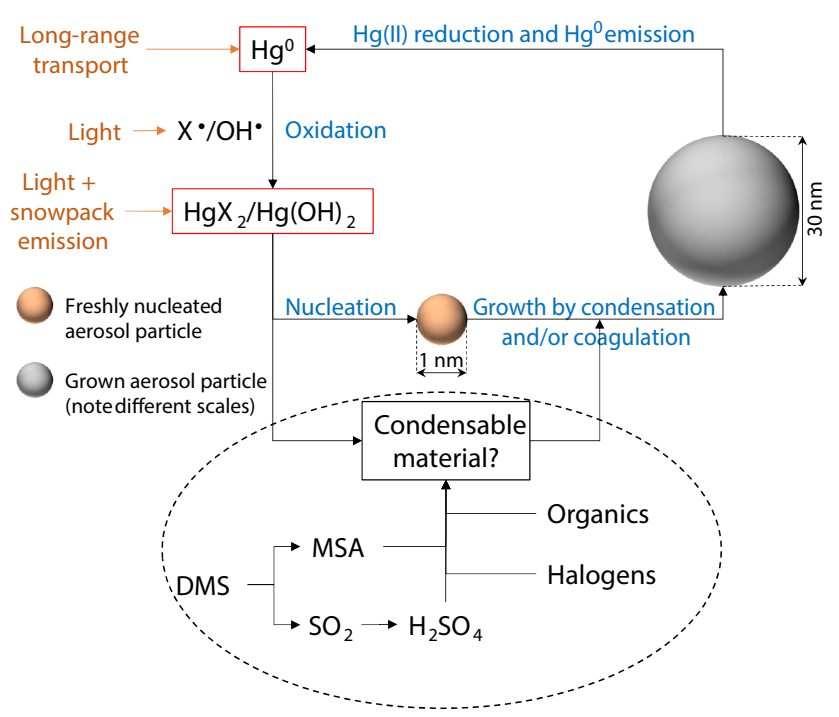

Figure 9. A suggested nucleation and growth mechanism driven by atmospheric mercury present from long-range transport. This chemistry is likely only to occur under conditions of low background aerosol surface area, otherwise these reaction products are more likely to adhere to pre-existing aerosol surfaces. Species highlighted in red constitute what is measured as TGM. Evidence suggests that no single species, DMS, organics, or halogens, can explain growth rates; however, they may combine into a single reservoir of condensable material that may contribute to the growth process.

scribed, and correlations in experimental data could be coincidental, rather than reflective of a causal relationship.

\section{Summary and discussion}

Aerosol concentrations at two size thresholds, together with ancillary atmospheric composition data, were used to investigate the only in situ particle formation event that occurred during the 32 days of measurements during a marine science voyage in the pack ice off the East Antarctic coast. The significant particle formation event occurred within a single, homogeneous air mass and resulted in $\mathrm{CN}_{3}$ particle concentrations reaching almost $7700 \mathrm{~cm}^{-3}$ within a few hours after being at background values under $400 \mathrm{~cm}^{-3}$. Formation rates of $3 \mathrm{~nm}$ particles ranged from 0.2 to $1.1 \pm 0.1 \mathrm{~cm}^{-3} \mathrm{~s}^{-1}$, higher than most events observed in the Antarctic region, and similar to a recently described rare continentally derived event (Kyrö et al., 2013). Estimated growth rates were higher than those previously observed in the region, being $5.6 \pm$ $0.9 \mathrm{~nm} \mathrm{~h}^{-1}$ during growth from 3 to $10 \mathrm{~nm}$ diameters. An assessment of the reduction in particle numbers found that loss processes were dominated by coagulation, with calculations yielding a coagulation coefficient of $(8 \pm 2) \times 10^{-9} \mathrm{~cm}^{-3} \mathrm{~s}^{-1}$, consistent with coagulation of particles with diameters, $D_{1}$ and $D_{2}$, and a $D_{1} / D_{2}$ ratio of $5.1 \pm 0.3$ (e.g. 3 and $17 \mathrm{~nm}$ particles), corresponding to the likely sizes present.
The event was characterised by pre-existing aerosol surface areas below $5 \mu \mathrm{m}^{2} \mathrm{~cm}^{-3}$, along with abnormally clear cloud conditions that resulted in incoming solar radiation fluxes higher than observed on any other day during the voyage, reaching over $600 \mathrm{~W} \mathrm{~m}^{-2}$ for $4 \mathrm{~h}$, and $700 \mathrm{Wm}^{-2}$ at midday.

An evaluation of the mechanism responsible for nucleation found that known sulfur, halogen or organic chemistry could not explain observed nucleation and growth rates. Statistically significant correlations were found to exist between $\mathrm{CN}_{3}$ and TGM concentrations, as well as incoming solar radiation. A mercury-driven nucleation mechanism is proposed as a plausible explanation for the observed nucleation.

The mercury present in this environment is a result of long-range transport from the significant anthropogenic and natural (e.g. volcanic) sources. This is possible because of the relatively long atmospheric lifetime of elemental mercury, $\mathrm{Hg}^{0}$, approximately 0.8 years (Selin et al., 2007). These sources often co-emit other species alongside $\mathrm{Hg}$, the most relevant for nucleation being $\mathrm{SO}_{2}$. Despite the high emissions of $\mathrm{SO}_{2}$ relative to $\mathrm{Hg}$ from these sources (the $\mathrm{Hg}: \mathrm{SO}_{2}$ emission ratio from degassing volcanoes is $10^{-4}-10^{-6}$; Pirrone et al., 2010), the short atmospheric lifetime ( $\sim 1$ day) of $\mathrm{SO}_{2}$ (Lee et al., 2011) suggests that its transport to this remote region is negligible compared with the significant local emissions (e.g. Curran and Jones, 2000) considered above.

Because of the instrumentation available for this voyage, the aerosol composition and nucleation chemistry could not be determined experimentally. It is plausible that instead of oxidised $\mathrm{Hg}$ (II) products nucleating homogeneously to form seeds, the $\mathrm{Hg}$ products combine with other low-volatility species such as $\mathrm{H}_{2} \mathrm{SO}_{4}$, forming the critical clusters and leading to growth. Additionally, other unidentified species may be responsible for this aerosol genesis. With further measurements utilising advanced instruments such as an atmospheric pressure ionisation time-of-flight mass spectrometer (API-ToF-MS; Junninen et al., 2010), cluster Chemical Ionisation Mass Spectrometer (CIMS; Zhao et al., 2010), or subnanometre instruments such as the Neutral cluster and Air Ion Spectrometer (NAIS; Asmi et al., 2009; Mirme et al., 2007), it may be possible to determine the chemistry that is occurring, including any involvement of mercury.

The box model employed here only included a simple DMS reaction scheme that lead to the production of $\mathrm{H}_{2} \mathrm{SO}_{4}$, which was included as the only condensing vapour. The code was modified for this study to include a simple parameterisation of MSA, which assumed the same properties as $\mathrm{H}_{2} \mathrm{SO}_{4}$ in the model (e.g. vapour pressure). This assumption, together with the MSA fractions used, meant that simulations represented the upper limit of condensible species originating from DMS. Given the upper limit was utilised, the uncertainty associated with this assumption is minimal in the final qualitative conclusion. This simple chemical scheme also meant that no other condensing species were included, suggesting heterogeneous reactions involving sulfur species and 
other unidentified compounds could have been possible, but have not been tested.

Explicit modelling of either mercury chemistry or cloud cycling was not included in this model. Mercury and its oxidation products undergo numerous reactions in the atmosphere, including oxidation and reduction, as well as within cloud droplets, where ion exchange and reduction reactions can occur (e.g. Selin et al., 2007). Additionally, the changes in chemical and physical properties of cloud cycling on aerosols, although not a major factor in this study because of the minimal influence of cloud during the measurement period, could be important in other environments. Further modelling work is required in future studies to enable better parameterisation of any mercury chemistry and partitioning that may occur, as well as the inclusion of interactions with clouds and the ice surface.

Although only one particle formation event was observed during this campaign, it is possible that similar events are occurring frequently in the Southern Ocean and Antarctic regions. If mercury chemistry is driving nucleation, necessary prerequisites include both high TGM concentrations $\left(\geq 1.5 \mathrm{ng} \mathrm{m}^{-3}\right.$ ) and high incident solar radiation, both of which only occurred simultaneously once during the measurement period. Although sustained periods of high TGM concentration were only observed once during this campaign, $\mathrm{Hg}^{0}$ concentrations in the lower latitudes and the $\mathrm{NH}$ are often found to be higher than those found during this voyage (Baker et al., 2002). Since transport of air masses from lower latitudes is relatively frequent, high TGM concentrations in the Antarctic region may be frequent.

The incident solar radiation was increasing consistently throughout the voyage. As summer approaches, the increasing solar radiation will provide ample photolytic conditions required for nucleation. Climatological data of mean daily sunshine hours from other stations in the Antarctic continent and Southern Ocean (Macquarie Island, Casey, Mawson and Davis stations were compared; http://www.bom.gov.au/) show that between 20 and $40 \%$ of daylight hours have direct sunshine (as measured by Campbell-Stokes recorder) between September and April, dependent primarily on location. Although this fraction is significantly higher than what was observed during this campaign, it suggests that many areas of the region provide sufficient photolytic conditions to allow this nucleation mechanism to occur frequently in the Antarctic boundary layer.

The photolytic release of oxidised mercury species from the snowpack, and subsequent nucleation, could be occurring in many other regions around the globe. Mercury depletion events were first reported from measurements in the Arctic springtime (Schroeder et al., 1998). It is possible that re-emission of deposited mercury compounds is occurring in both polar regions, resulting in sufficient atmospheric concentrations under suitable photolytic conditions for aerosol nucleation to occur. Additionally, other surface emissions of reactive gaseous mercury, which are substantial around the globe (United Nations Environmental Programme, 2013), could lead to nucleation when pre-existing aerosol surface areas are low enough.

The prerequisites for nucleation via this mechanism are unlikely to be confined to the polar boundary layer. Conditions of low pre-existing aerosol surface area are common above clouds in the free troposphere and stratosphere. Coincidentally, these locations also experience high levels of solar radiation. In the Northern Hemisphere in particular, TGM concentrations are also likely to be sufficient at these altitude levels given the significantly higher boundary layer concentrations (Schroeder and Munthe, 1998; Slemr et al., 2003). This suggests that this nucleation mechanism could be occurring throughout the atmosphere.

Other high mercury, low particle environments may also host this type of nucleation. Coal-fired power plants are one of the largest sources of mercury in most countries, with an estimated $25 \%$ of global anthropogenic emissions to the atmosphere (United Nations Environmental Programme, 2013). Power plant exhaust plumes can have TGM concentrations enhanced up to $6.4 \mathrm{ng} \mathrm{m}^{-3}$ above ambient concentrations (Deeds et al., 2013) that are commonly much higher than those observed here (e.g. ambient concentrations at Alert Station in the Canadian Arctic are 2 and over $5 \mathrm{ng} \mathrm{m}^{-3}$ in Asia, United Nations Environmental Programme, 2008). Filtering of primary particulate emissions from power plant exhaust is mandatory in many countries around the world. Within these plumes, it is possible that the ratio between $\mathrm{Hg}^{0}$ concentrations and pre-existing aerosol surface area is high enough that secondary particle formation driven by mercury is possible. If this were the case, this chemistry could lead to an additional aerosol burden in industrial environments, which should be quantified.

The correlations between nucleation mode aerosol and mercury observations, and thus the proposal of this mechanism, have likely not been suggested before because coincident measurements of particle formation events and mercury are rare. These two measurements only occurred in this study serendipitously. Additionally, high aerosol concentrations in commonly sampled areas result in reactive, low-volatility mercury products being scavenged by pre-existing particles, removing them from the atmosphere and preventing their nucleation.

It is important to note that the assumption used in this work, i.e. the transmission efficiency of the aerosol sample inlet was the same across all sizes (discussed in Sect. 2.2), is flawed, particularly at sizes below $10 \mathrm{~nm}$. If better characterisation of the inlet were possible at the sub- $10 \mathrm{~nm}$ size range, it is likely that $\mathrm{CN}_{3-10}$ would increase significantly ( $\sim 50 \%$ ), which would increase both formation and loss rates. If this correction were applied and $\mathrm{CN}_{3-10}$ number concentrations increased, the problems associated with the model's inability to reproduce observations would be exacerbated and strengthen the major conclusions of this work. 
Results described here represent only a basic measurement suite. More detailed measurements of aerosols, including full size distributions and chemical and elemental composition (e.g. fractions of organic matter, sea salt, sulfate, or other species such as mercury), as well as detailed mercury and sulfur speciation, are necessary for full experimental characterisation of this chemistry. Further aerosol focussed studies are necessary in this environment to more completely characterise the aerosol loading as well as the frequency and impact of new particle formation. Ideally, these measurements would be both campaign based and long term (e.g. the Obuoy system, Knepp et al., 2010), although the latter presents significant logistical challenges in the dynamic sea ice zone. Laboratory (in particular chamber studies) and modellingbased studies would help to determine, both qualitatively and quantitatively, whether this chemistry has any atmospheric significance. If substantiated through further observations, the newly described chemistry could be important in regions where pre-existing aerosol populations and resulting scavenging rates of oxidised mercury products are low. 


\section{Appendix A: Mercury depletion on 17 October}

As discussed in the main text, the high total gaseous mercury (TGM) concentrations on 18 October followed a significant depletion that occurred on 17 October, as shown in Appendix Fig. 1. The depletion corresponded directly to very high concentrations of $\mathrm{BrO}$ and is likely a sign of well-known $\mathrm{BrO}-$ $\mathrm{Hg}$ chemistry that leads to deposition of $\mathrm{Hg}$ compounds onto the snow surface.

\section{Appendix B: Assessing halogens as $\mathrm{Hg}^{0}$ oxidants}

Halogen radical species cannot currently be measured directly; however, profiles of $\mathrm{IO}$ and $\mathrm{BrO}$, close proxies for I and $\mathrm{Br}$, respectively, in the lowest $4 \mathrm{~km}$ of the atmosphere were derived from MAX-DOAS observations during the voyage. Both oxidised species are a single step away from their respective atomic radicals in their reaction chemistry, and as such, are a good proxy for their radical chemistry.

As previously discussed, measured concentrations of IO during the event were below $0.1 \mathrm{pptv}(\sim 2.7 \times$ $10^{6}$ molec $\mathrm{cm}^{-3}$ ), making iodine compounds acting as oxidants in the chemistry unlikely. Total column amounts of $\mathrm{BrO}$ were below $1 \times 10^{5}$ molec $^{-2}$ on this day, with no vertical gradient observed. Other periods of mercury depletion were observed during the voyage that were associated with elevated $\mathrm{BrO}$ concentrations well above detection limit (for example October 17) in chemistry well-known as mercury depletion events. Recent measurements by Liao et al. (2014) suggest that a lack of BrO could suggest an abundance of $\mathrm{Br}_{2}$ instead. Data from the same study shows that the concentration of $\mathrm{Br}_{2}$ varies inversely with $\mathrm{O}_{3}$, with high $\mathrm{Br}_{2}$ levels observed only when ozone is depleted. The high concentration and lack of variation in $\mathrm{O}_{3}$ on the 18 October makes the presence of $\mathrm{Br}_{2}$ unlikely. Despite these low concentrations of $\mathrm{BrO}$, the fast rate constant suggests that it is still a prime candidate for the oxidant of this event (Stephens et al., 2012).

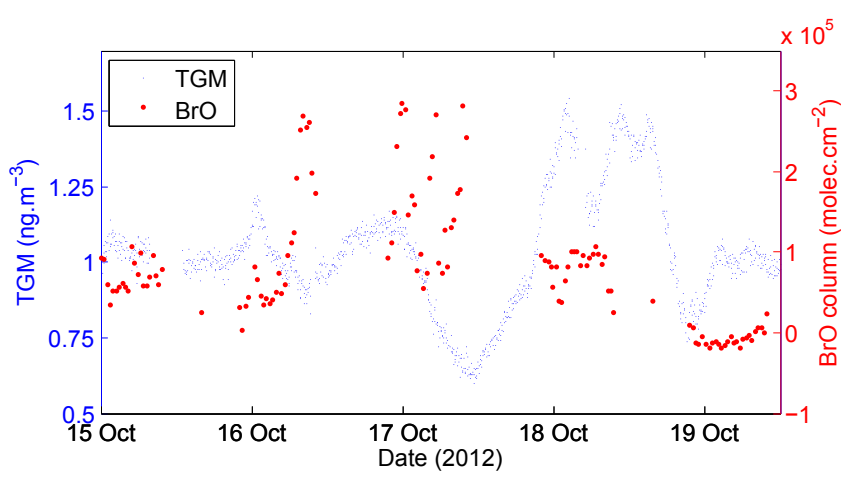

Figure B1. Total gaseous mercury (TGM) and column BrO from the MAX-DOAS instrument. The 17 October experiences significant concentrations of $\mathrm{BrO}$, along with simultaneous depletion of TGM, just prior to the 18 October nucleation event.

No measurements of reactive $\mathrm{Cl}$ compounds were made during the voyage other than chlorinated halocarbons using GC-ECD. Halocarbons are sources of reactive halogen species (e.g. O'Dowd et al., 2002b) and can therefore be used as a proxy. None of the six measured halogen compounds $\left(\mathrm{CH}_{3} \mathrm{I}, \mathrm{C}_{2} \mathrm{Cl}_{4}, \mathrm{CH}_{3} \mathrm{CCl}_{3}, \mathrm{CHCl}_{3}, \mathrm{CH}_{2} \mathrm{Br}_{2}\right.$ and $\mathrm{CHBr}_{3}$ ) showed any deviation from background in the days surrounding the event. These measurements suggest, although not definitively, that $\mathrm{Cl}$ is an unlikely oxidant of this event. Recent work in the Arctic (Stephens et al., 2012) found that although $\mathrm{Br}$ and $\mathrm{Cl}$ are found in similar concentrations, the rates of reaction of the two result in $\mathrm{Br}$ being the dominant oxidant in this environment. Precursors of $\mathrm{Cl}$ have common sources with other halogen precursors, and are currently believed to include hypersaline brine surfaces on young sea ice, frost flowers, surface hoar adjacent to refreezing leads, saline snowpacks and sea salt aerosol (Foster et al., 2001; Kaleschke, 2004; Douglas, 2005; Simpson et al., 2007; Saiz-Lopez and von Glasow, 2012; Stephens et al., 2012). The release of chlorine can also be triggered by photochemical processes (Saiz-Lopez and von Glasow, 2012), which is consistent with the photochemical nature of the observed nucleation event. It is unclear, however, whether $\mathrm{Cl}$ occurs in significant concentrations when the concentrations of other halogen species are so low. 

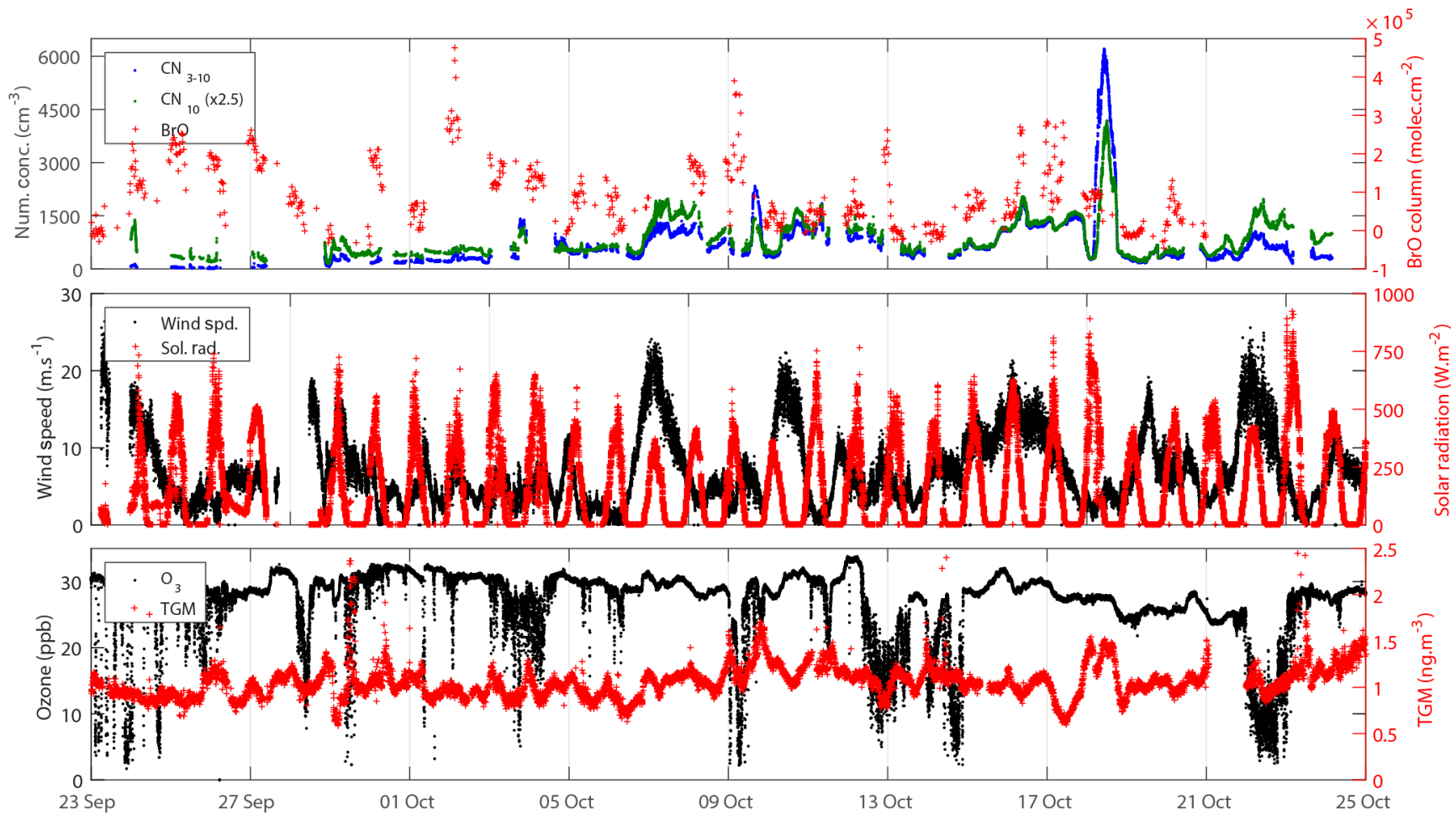

Figure B2. Time series of the full 32 days of measurements of aerosol number concentrations, along with simultaneous measurements of $\mathrm{BrO}$, wind speed, solar radiation, ozone and total gaseous mercury. The 18 October stands out with low BrO and wind speed, high TGM and solar radiation, and no change in ozone. 


\section{Data availability}

Data from the voyage are available at the Australian Antarctic Data Centre (AADC). Data set DOIs will be made public upon publication.

Author contributions. R. Humphries wrote the manuscript, led the overall data analysis and interpretation, ran all instruments, except the Tekran, during the field campaign, performed quality control on aerosol, and ran the box model and interpreted the results. R. Schofield led AAS project 4032, and was instrumental in the field campaign and data analysis. M. Keywood and J. Ward provided aerosol instrumentation. J. Pierce provided the box model, and assisted in its commissioning. C. Gionfriddo, M. Tate and D. Krabbenhoft provided, ran and performed quality control on Hg data. I. Galbally and S. Molloy provided and installed ozone instrumentation while I. Galbally, S. Molloy, A. Klekociuk and R. Humphries performed quality control. P. Johnston, K. Kreher and $\mathrm{A}$. Thomas provided the instrument, technical support and analysis of data from the MAX-DOAS. A. Robinson, N. Harris and A. Thomas provided the GC-ECD instrument. A. Robinson and N. Harris performed GC-ECD data quality control and running algorithms. R. Johnson produced chlorophyll data from fluorescence measurements. S. Wilson and R. Humphries calculated $\mathrm{OH}$ concentrations. R. Schofield, M. Keywood and S. Wilson provided academic support.

Acknowledgements. This research was funded by the Australian Antarctic Science Grant Programme (AAS project 4032). Additional support was also provided by the CSIRO OCE Postgraduate Top-Up Scholarship. We would also like to thank the SIPEXII team and the Australian Antarctic Division for logistics and technical support during the campaign, in particular L. Symons, K. Briggs, M. Jordan, M. Longmire, I. McLean, J. Reeve and K. Meiners. We thank R. Chang and F. Yu for assistance in model commissioning. Development of the $\mu$ Dirac was funded by the UK Natural Environmental Research Council (NERC). We thank A. Gordon for running the peak analysis software for the $\mu$ Dirac. N. Harris and A. Robinson would like to thank NERC for financial support through an Advanced Research Fellowship and the CAST project.

Edited by: P. DeCarlo

\section{References}

Adams, P. J. and Seinfeld, J. H.: Predicting global aerosol size distributions in general circulation models, J. Geophys. Res., 107, 4370, doi:10.1029/2001JD001010, 2002.

Ariya, P. A., Khalizov, A., and Gidas, A.: Reactions of Gaseous Mercury with Atomic and Molecular Halogens: Kinetics, Product Studies, and Atmospheric Implications, J. Phys. Chem. A, 106, 7310-7320, doi:10.1021/jp020719o, 2002.

Asmi, E., Sipilä, M., Manninen, H. E., Vanhanen, J., Lehtipalo, K., Gagné, S., Neitola, K., Mirme, A., Mirme, S., Tamm, E., Uin, J., Komsaare, K., Attoui, M., and Kulmala, M.: Results of the first air ion spectrometer calibration and intercomparison workshop, Atmos. Chem. Phys., 9, 141-154, doi:10.5194/acp-9-141-2009, 2009.

Asmi, E., Frey, A., Virkkula, A., Ehn, M., Manninen, H. E., Timonen, H., Tolonen-Kivimäki, O., Aurela, M., Hillamo, R., and Kulmala, M.: Hygroscopicity and chemical composition of Antarctic sub-micrometre aerosol particles and observations of new particle formation, Atmos. Chem. Phys., 10, 4253-4271, doi:10.5194/acp-10-4253-2010, 2010.

Atkinson, H. M., Huang, R.-J., Chance, R., Roscoe, H. K., Hughes, C., Davison, B., Schönhardt, A., Mahajan, A. S., Saiz-Lopez, A., Hoffmann, T., and Liss, P. S.: Iodine emissions from the sea ice of the Weddell Sea, Atmos. Chem. Phys., 12, 11229-11244, doi:10.5194/acp-12-11229-2012, 2012.

Ayers, G. P. and Gras, J. L.: Ammonia gas concentrations over the Southern Ocean, Nature, 284, 539-540, 1980.

Baker, P., Brunke, E.-G., Slemr, F., and Crouch, A.: Atmospheric mercury measurements at Cape Point, South Africa, Atmos. Environ., 36, 2459-2465, doi:10.1016/S1352-2310(01)00531-3, 2002.

Belosi, F., Contini, D., Donateo, A., Santachiara, G., and Prodi, F. Aerosol size distribution at Nansen Ice Sheet Antarctica, Atmos. Res., 107, 42-50, 2012.

Bork, N., Elm, J., Olenius, T., and Vehkamäki, H.: Methane sulfonic acid-enhanced formation of molecular clusters of sulfuric acid and dimethyl amine, Atmos. Chem. Phys., 14, 12023 12030, doi:10.5194/acp-14-12023-2014, 2014.

Boudries, H. and Bottenheim, J. W.: $\mathrm{Cl}$ and $\mathrm{Br}$ atom concentrations during a surface boundary layer ozone depletion event in the Canadian High Arctic, Geophys. Res. Lett., 27, 517-520, doi:10.1029/1999GL011025, 2000.

Bloss, W. J., Lee, J. D., Heard, D. E., Salmon, R. A., Bauguitte, S. J.-B., Roscoe, H. K., and Jones, A. E.: Observations of $\mathrm{OH}$ and $\mathrm{HO}_{2}$ radicals in coastal Antarctica, Atmos. Chem. Phys., 7, 4171-4185, doi:10.5194/acp-7-4171-2007, 2007.

Bzdek, B. R., Ridge, D. P., and Johnston, M. V.: Reactivity of methanesulfonic acid salt clusters relevant to marine air, J. Geophys. Res., 116, D03301, doi:10.1029/2010JD015217, 2011.

Calvert, J. and Lindberg, S.: Mechanisms of mercury removal by $\mathrm{O}$ and $\mathrm{OH}$ in the atmosphere, Atmos. Environ., 39, 3355-3367, doi:10.1016/j.atmosenv.2005.01.055, 2005.

Carslaw, K. S., Lee, L. A., Reddington, C. L., Pringle, K. J., Rap, A., Forster, P. M., Mann, G. W., Spracklen, D. V., Woodhouse, M. T., Regayre, L. A., and Pierce, J. R.: Large contribution of natural aerosols to uncertainty in indirect forcing, Nature, 503, 67-71, doi:10.1038/nature12674, 2013.

Chang, R. Y.-W., Sjostedt, S. J., Pierce, J. R., Papakyriakou, T. N., Scarratt, M. G., Michaud, S., Levasseur, M., Leaitch, W. R., and Abbatt, J. P. D.: Relating atmospheric and oceanic DMS levels to particle nucleation events in the Canadian Arctic, J. Geophys. Res., 116, D00S03, doi:10.1029/2011JD015926, 2011.

Chen, L., Wang, J., Gao, Y., Xu, G., Yang, X., Lin, Q., and Zhang, Y.: Latitudinal distributions of atmospheric MSA and MSA/nss$\mathrm{SO}_{4}^{2-}$ ratios in summer over the high latitude regions of the Southern and Northern Hemispheres, J. Geophys. Res., 117, D10306, doi:10.1029/2011JD016559, 2012.

Chin, M., Jacob, D. J., Gardner, G. M., Foreman-Fowler, M. S., Spiro, P. A., and Savoie, D. L.: A global three-dimensional 
model of tropospheric sulfate, J. Geophys. Res., 101, 18667, doi:10.1029/96JD01221, 1996.

Clarke, A. D., Varner, J. L., Eisele, F., Mauldin, R. L., Tanner, D., and Litchy, M.: Particle production in the remote marine atmosphere: Cloud outflow and subsidence during ACE 1, J. Geophys. Res.-Atmos., 103, 16397-16409, doi:10.1029/97jd02987, 1998.

Covert, D. S., Kapustin, V. N., Quinn, P. K., and Bates, T. S.: New particle formation in the marine boundary layer, J. Geophys. Res., 97, 20581, doi:10.1029/92JD02074, 1992.

Covert, D. S., Wiedensohler, A., Aalto, P., Heintzenberg, J., McMurry, P. H., and Leck, C.: Aerosol number size distributions from 3 to $500 \mathrm{~nm}$ diameter in the arctic marine boundary layer during summer and autumn, Tellus B, 48, 197-212, 1996.

Creasey, D. J., Evans, G. E., Heard, D. E., and Lee, J. D.: Measurements of $\mathrm{OH}$ and $\mathrm{HO}_{2}$ concentrations in the Southern Ocean marine boundary layer, J. Geophys. Res., 108, 4475, doi:10.1029/2002JD003206, 2003.

Curran, M. A. J. and Jones, G. B.: Dimethyl sulfide in the Southern Ocean: Seasonality and flux, J. Geophys. Res., 105, 20451, doi:10.1029/2000JD900176, 2000.

Dall'Osto, M., Ceburnis, D., Monahan, C., Worsnop, D. R., Bialek, J., Kulmala, M., Kurtén, T., Ehn, M., Wenger, J., Sodeau, J., Healy, R., and O'Dowd, C.: Nitrogenated and aliphatic organic vapors as possible drivers for marine secondary organic aerosol growth, J. Geophys. Res.-Atmos., 117, D12311, doi:10.1029/2012JD017522, 2012.

Davis, D., Chen, G., Kasibhatla, P., Jefferson, A., Tanner, D., Eisele, F., Lenschow, D., Neff, W., and Berresheim, H.: DMS oxidation in the Antarctic marine boundary layer: Comparison of model simulations and held observations of DMS, DMSO, $\mathrm{DMSO}_{2}$, $\mathrm{H}_{2} \mathrm{SO}_{4}(\mathrm{~g}), \mathrm{MSA}(\mathrm{g})$, and MSA(p), J. Geophys. Res., 103, 1657, doi:10.1029/97JD03452, 1998.

Davison, B., Hewitt, C. N., O'Dowd, C. D., Lowe, J. A., Smith, M. H., Schwikowski, M., Baltensperger, U., and Harrison, R. M.: Dimethyl sulfide, methane sulfonic acid and physicochemical aerosol properties in Atlantic air from the United Kingdom to Halley Bay, J. Geophys. Res., 101, 22855-22867, doi:10.1029/96jd01166, 1996.

Dawson, M. L., Varner, M. E., Perraud, V., Ezell, M. J., Gerber, R. B., and Finlayson-Pitts, B. J.: Simplified mechanism for new particle formation from methanesulfonic acid, amines, and water via experiments and ab initio calculations., P. Natl. Acad. Sci. USA, 109, 18719-18724, doi:10.1073/pnas.1211878109, 2012.

Deeds, D. A., Banic, C. M., Lu, J., and Daggupaty, S.: Mercury speciation in a coal-fired power plant plume: An aircraft-based study of emissions from the 3640 MW Nanticoke Generating Station, Ontario, Canada, J. Geophys. Res.-Atmos., 118, 49194935, doi:10.1002/jgrd.50349, 2013.

Dibble, T. S., Zelie, M. J., and Mao, H.: Thermodynamics of reactions of $\mathrm{ClHg}$ and $\mathrm{BrHg}$ radicals with atmospherically abundant free radicals, Atmos. Chem. Phys., 12, 10271-10279, doi:10.5194/acp-12-10271-2012, 2012.

Douglas, T. A.: Elevated mercury measured in snow and frost flowers near Arctic sea ice leads, Geophys. Res. Lett., 32, L04502, doi:10.1029/2004GL022132, 2005.

Draxler, R. R. and Hess, G. D.: An Overview of the HYSPLIT_4 Modelling System for Trajectories, Dispersion, and Deposition, Aust. Meteorol. Mag., 47, 295-308, 1998.
Ebinghaus, R., Kock, H. H., Temme, C., Einax, J. W., Löwe, A. G., Richter, A., Burrows, J. P., and Schroeder, W. H.: Antarctic Springtime Depletion of Atmospheric Mercury, Environ. Sci. Technol., 36, 1238-1244, doi:10.1021/es015710z, 2002.

Ehn, M., Thornton, J. A., Kleist, E., Sipilä, M., Junninen, H., Pullinen, I., Springer, M., Rubach, F., Tillmann, R., Lee, B., LopezHilfiker, F., Andres, S., Acir, I.-H., Rissanen, M., Jokinen, T., Schobesberger, S., Kangasluoma, J., Kontkanen, J., Nieminen, T., Kurtén, T., Nielsen, L. B., Jørgensen, S., Kjaergaard, H. G., Canagaratna, M., Maso, M. D., Berndt, T., Petäjä, T., Wahner, A., Kerminen, V.-M., Kulmala, M., Worsnop, D. R., Wildt, J., and Mentel, T. F.: A large source of low-volatility secondary organic aerosol, Nature, 506, 476-9, doi:10.1038/nature13032, 2014.

Feddersen, D. M., Talbot, R., Mao, H., and Sive, B. C.: Size distribution of particulate mercury in marine and coastal atmospheres, Atmos. Chem. Phys., 12, 10899-10909, doi:10.5194/acp-1210899-2012, 2012.

Foster, K. L., Plastridge, R. A., Bottenheim, J. W., Shepson, P. B., Finlayson-Pitts, B. J., and Spicer, C. W.: The role of $\mathrm{Br} 2$ and $\mathrm{BrCl}$ in surface ozone destruction at polar sunrise., Science, 291, 471-4, doi:10.1126/science.291.5503.471, 2001.

Frieß, U., Wagner, T., Pundt, I., Pfeilsticker, K., and Platt, U.: Spectroscopic measurements of tropospheric iodine oxide at Neumayer Station, Antarctica, Geophys. Res. Lett., 28, 1941-1944, doi:10.1029/2000g1012784, 2001.

Frieß, U., Deutschmann, T., Gilfedder, B. S., Weller, R., and Platt, U.: Iodine monoxide in the Antarctic snowpack, Atmos. Chem. Phys., 10, 2439-2456, doi:10.5194/acp-10-2439-2010, 2010.

Galbally, I. E., Molloy, S. B., Klekociuk, A. R., Humphries, R. S., and Schofield, R.: In-situ atmospheric ozone measurements observed during the SIPEX II voyage of the Aurora Australis, 2012, Australian Antarctic Data Centre, Australia, doi:10.4225/15/53266BE438281, 2014.

Gionfriddo, C. M., Tate, M. T., Krabbenhoft, D. P., Moreau, J., and Schofield, R.: Gaseous elemental mercury measurements of boundary layer air made by a Tekran 2537 during the SIPEX II voyage of the Aurora Australis, 2012, Australian Antarctic Data Centre, Australia, doi:10.4225/15/53266BDA687FC, 2014.

Gostlow, B., Robinson, A. D., Harris, N. R. P., O’Brien, L. M., Oram, D. E., Mills, G. P., Newton, H. M., Yong, S. E., and A Pyle, J.: $\mu$ Dirac: an autonomous instrument for halocarbon measurements, Atmos. Meas. Tech., 3, 507-521, doi:10.5194/amt-3507-2010, 2010.

Graf, H.-F., Shirsat, S. V., Oppenheimer, C., Jarvis, M. J., Podzun, R., and Jacob, D.: Continental scale Antarctic deposition of sulphur and black carbon from anthropogenic and volcanic sources, Atmos. Chem. Phys., 10, 2457-2465, doi:10.5194/acp-10-24572010, 2010.

Gras, J. L.: Ammonia and ammonium concentrations in the Antarctic atmosphere, Atmos. Environm., 17, 815-818, 1983.

Gras, J. L.: Condensation nucleus size distribution at Mawson, Antarctica: seasonal cycle, Atmos. Environ.-A Gen., 27, 14171425, doi:10.1016/0960-1686(93)90127-K, 1993.

Heintzenberg, J., Birmili, W., Wiedensohler, A., Nowak, A., and Tuch, T.: Structure, variability and persistence of the submicrometre marine aerosol, Tellus B, 56, 357-367, doi:10.3402/tellusb.v56i4.16450, 2004.

Hoffmann, T., Odum, J. R., Bowman, F., Collins, D., Klockow, D., Flagan, R. C., and Seinfeld, J. H.: Formation of Organic Aerosols 
from the Oxidation of Biogenic Hydrocarbons, J. Atmos. Chem., 26, 189-222, doi:10.1023/A:1005734301837, 1997.

Hu, Q.-H., Xie, Z.-Q., Wang, X.-M., Kang, H., He, Q.-F., and Zhang, P.: Secondary organic aerosols over oceans via oxidation of isoprene and monoterpenes from Arctic to Antarctic., Sci. Rep., 3, 2280, doi:10.1038/srep02280, 2013.

Humphries, R. S., Wilson, S. R., Keywood, M. D., Ward, J., and Schofield, R.: In-situ total aerosol number using condensation particle counters as observed during the SIPEX II voyage of the Aurora Australis, 2012, Australian Antarctic Data Centre, Australia, doi:10.4225/15/5342423241BE4, 2014.

Humphries, R. S., Klekociuk, A. R., Schofield, R., Keywood, M. D., Ward, J., and Wilson, S. R.: Unexpectedly high ultrafine aerosol concentrations above East Antarctic sea-ice, Atmos. Chem. Phys. Discuss., 15, 29125-29170, doi:10.5194/acpd-15-29125-2015, 2015.

Hynes, A. J., Donohoue, D. L., Goodsite, M. E., and Hedgecock, I. M.: Our Current Understanding of Major Chemical and Physical Processes Affecting Mercury Dynamics in the Atmosphere and At the Air-Water/Terrestrial Interfaces, in: Mercury Fate and Transport in the Global Atmosphere, edited by: Mason, R. and Pirrone, N., Springer US, Boston, MA, 427-457, doi:10.1007/978-0-387-93958-2, 2009.

International Programme on Chemical Safety, I.: INCHEM Mercuric Oxide, http://www.inchem.org/documents/icsc/icsc/ eics0981.htm (last access: 30 November 2015), 2001.

IPCC: Climate Change 2013: The Physical Science Basis. Contribution of Working Group I to the Fifth Assessment Report of the Intergovernmental Panel on Climate Change, Cambridge University Press, Cambridge, United Kingdom and New York, NY, USA, doi:10.1017/CBO9781107415324, www. climatechange2013.org (last access: 30 November 2015), 2013.

Järvinen, E., Virkkula, A., Nieminen, T., Aalto, P. P., Asmi, E., Lanconelli, C., Busetto, M., Lupi, A., Schioppo, R., Vitale, V., Mazzola, M., Petäjä, T., Kerminen, V.-M., and Kulmala, M.: Seasonal cycle and modal structure of particle number size distribution at Dome C, Antarctica, Atmos. Chem. Phys., 13, 7473-7487, doi:10.5194/acp-13-7473-2013, 2013.

Junninen, H., Ehn, M., Petäjä, T., Luosujärvi, L., Kotiaho, T., Kostiainen, R., Rohner, U., Gonin, M., Fuhrer, K., Kulmala, M., and Worsnop, D. R.: A high-resolution mass spectrometer to measure atmospheric ion composition, Atmos. Meas. Tech., 3, 1039 1053, doi:10.5194/amt-3-1039-2010, 2010.

Kaleschke, L.: Frost flowers on sea ice as a source of sea salt and their influence on tropospheric halogen chemistry, Geophys. Res. Lett., 31, L16114, doi:10.1029/2004GL020655, 2004.

Karl, M., Gross, A., Leck, C., and Pirjola, L.: Intercomparison of dimethylsulfide oxidation mechanisms for the marine boundary layer: Gaseous and particulate sulfur constituents, J. Geophys. Res., 112, D15304, doi:10.1029/2006JD007914, 2007.

Kirkby, J., Curtius, J., Almeida, J. J., Dunne, E., Duplissy, J., Ehrhart, S., Franchin, A., Gagne, S., Ickes, L., Kurten, A., Kupc, A., Metzger, A., Riccobono, F., Rondo, L., Schobesberger, S., Tsagkogeorgas, G., Wimmer, D., Amorim, A., Bianchi, F., Breitenlechner, M., David, A. A., Dommen, J., Downard, A., Ehn, M., Flagan, R. C., Haider, S., Hansel, A., Hauser, D., Jud, W., Junninen, H., Kreissl, F., Kvashin, A., Laaksonen, A., Lehtipalo, K., Lima, J., Lovejoy, E. R., Makhmutov, V., Mathot, S., Mikkila, J., Minginette, P., Mogo, S., Nieminen, T., Onnela, A., Pereira, P.,
Petaja, T., Schnitzhofer, R., Seinfeld, J. H., Sipila, M., Stozhkov, Y., Stratmann, F., Tome, A., Vanhanen, J., Viisanen, Y., Vrtala, A., Wagner, P. E., Walther, H., Weingartner, E., Wex, H., Winkler, P. M., Carslaw, K. S., Worsnop, D. R., Baltensperger, U., Kulmala, M., Gagné, S., Kürten, A., Mikkilä, J., Petäjä, T., Sipilä, M., and Tomé, A.: Role of sulphuric acid, ammonia and galactic cosmic rays in atmospheric aerosol nucleation, Nature, 476, 429-433, doi:10.1038/nature10343, 2011.

Klekociuk, A. R. and Schofield, R.: Hysplit atmospheric backtrajectories at $10 \mathrm{~m}, 500 \mathrm{~m}, 1000 \mathrm{~m}, 1500 \mathrm{~m}, 2000 \mathrm{~m}, 2500 \mathrm{~m}$, $3000 \mathrm{~m}, 3500 \mathrm{~m}, 4000 \mathrm{~m}$ collected during the SIPEX II voyage of the Aurora Australis, 2012. Australian Antarctic Data Centre, Australia, doi:10.4225/15/532F83302FF88, 2014.

Klekociuk, A. R., Schofield, R., Humphries, R. S., Galbally, I. E., Molloy, S. B., Alexander, S. P., Fraser, A., and Tully, M. B.: Characteristics of Surface Ozone between Australia and Antarctica observed during the SIPEX-I and -II Cruises, in preparation, 2015.

Knepp, T. N., Bottenheim, J., Carlsen, M., Carlson, D., Donohoue, D., Friederich, G., Matrai, P. A., Netcheva, S., Perovich, D. K., Santini, R., Shepson, P. B., Simpson, W., Valentic, T., Williams, C., and Wyss, P. J.: Development of an autonomous sea ice tethered buoy for the study of ocean-atmosphere-sea ice-snow pack interactions: the O-buoy, Atmos. Meas. Tech., 3, 249-261, doi:10.5194/amt-3-249-2010, 2010.

Koponen, I. K., Virkkula, A., Hillamo, R., Kerminen, V.-M., and Kulmala, M.: Number size distributions and concentrations of marine aerosols: Observations during a cruise between the English Channel and the coast of Antarctica, J. Geophys. Res., 107, 4753, doi:10.1029/2002JD002533, 2002.

Koponen, I. K., Virkkula, A., Hillamo, R., Kerminen, V.-M., and Kulmala, M.: Number size distributions and concentrations of the continental summer aerosols in Queen Maud Land, Antarctica, J. Geophys. Res.-Atmos., 108, 4587, doi:10.1029/2003jd003614, 2003.

Korhonen, P., Kulmala, M., Laaksonen, A., Viisanen, Y., McGraw, R., and Seinfeld, J. H.: Ternary nucleation of $\mathrm{H}_{2} \mathrm{SO}_{4}, \mathrm{NH}_{3}$, and $\mathrm{H}_{2} \mathrm{O}$ in the atmosphere, J. Geophys. Res., 104, 26349, doi:10.1029/1999JD900784, 1999.

Kulmala, M., Vehkamäki, H., Petäjä, T., Dal Maso, M., Lauri, A., Kerminen, V. M., Birmili, W., and McMurry, P. H. Formation and growth rates of ultrafine atmospheric particles: a review of observations, J. Aerosol Sci., 35, 143-176, doi:10.1016/j.jaerosci.2003.10.003, 2004.

Kukui, A., Legrand, M., Preunkert, S., Frey, M. M., Loisil, R., Gil Roca, J., Jourdain, B., King, M. D., France, J. L., and Ancellet, G.: Measurements of $\mathrm{OH}$ and $\mathrm{RO}_{2}$ radicals at Dome C, East Antarctica, Atmos. Chem. Phys., 14, 12373-12392, doi:10.5194/acp-14-12373-2014, 2014.

Kyrö, E.-M., Kerminen, V.-M., Virkkula, A., Dal Maso, M., Parshintsev, J., Ruíz-Jimenez, J., Forsström, L., Manninen, H. E., Riekkola, M.-L., Heinonen, P., and Kulmala, M.: Antarctic new particle formation from continental biogenic precursors, Atmos. Chem. Phys., 13, 3527-3546, doi:10.5194/acp-13-3527-2013, 2013.

Lee, C., Martin, R. V., Van Donkelaar, A., Lee, H., Dickerson, R. R., Hains, J. C., Krotkov, N., Richter, A., Vinnikov, K., and Schwab, J. J.: SO2 emissions and lifetimes: Estimates from inverse modeling using in situ and global, space-based (SCIA- 
MACHY and OMI) observations, J. Geophys. Res.-Atmos., 116, 1-13, doi:10.1029/2010JD014758, 2011.

Legrand, M., Ducroz, F., Wagenbach, D., Mulvaney, R., and Hall, J.: Ammonium in coastal Antarctic aerosol and snow: Role of polar ocean and penguin emissions, J. Geophys. Res., 103, 11043, doi:10.1029/97JD01976, 1998.

Liao, J., Huey, L. G., Liu, Z., Tanner, D. J., Cantrell, C. A., Orlando, J. J., Flocke, F. M., Shepson, P. B., Weinheimer, A. J., Hall, S. R., Ullmann, K., Beine, H. J., Wang, Y., Ingall, E. D., Stephens, C. R., Hornbrook, R. S., Apel, E. C., Riemer, D., Fried, A., Mauldin III, R. L., Smith, J. N., Staebler, R. M., Neuman, J. A., and Nowak, J. B.: High levels of molecular chlorine in the Arctic atmosphere, Nat. Geosci., 7, 91-94, doi:10.1038/ngeo2046, 2014.

Lindberg, S. E., Brooks, S., Lin, C. J., Scott, K. J., Landis, M. S., Stevens, R. K., Goodsite, M., and Richter, A.: Dynamic Oxidation of Gaseous Mercury in the Arctic Troposphere at Polar Sunrise, Environ. Sci. Technol., 36, 1245-1256, doi:10.1021/es0111941, 2002.

Lu, J. Y., Schroeder, W. H., Barrie, L. A., Steffen, A., Welch, H. E., Martin, K., Lockhart, L., Hunt, R. V., Boila, G., and Richter, A.: Magnification of atmospheric mercury deposition to polar regions in springtime: The link to tropospheric ozone depletion chemistry, Geophys. Res. Lett., 28, 3219-3222, doi:10.1029/2000GL012603, 2001.

Mauldin, R., Kosciuch, E., Henry, B., Eisele, F., Shetter, R., Lefer, B., Chen, G., Davis, D., Huey, G., and Tanner, D.: Measurements of $\mathrm{OH}, \mathrm{HO} 2+\mathrm{RO} 2, \mathrm{H} 2 \mathrm{SO} 4$, and $\mathrm{MSA}$ at the South Pole during ISCAT 2000, Atmos. Environ., 38, 5423-5437, doi:10.1016/j.atmosenv.2004.06.031, 2004.

Mauldin, R. L., Eisele, F. L., Tanner, D. J., Kosciuch, E., Shetter, R., Lefer, B., Hall, S. R., Nowak, J. B., Buhr, M., Chen, G., Wang, P., and Davis, D.: Measurements of $\mathrm{OH}, \mathrm{H}_{2} \mathrm{SO}_{4}$, and MSA at the South Pole during ISCAT, Geophys. Res. Lett., 28, 3629-3632, doi:10.1029/2000GL012711, 2001.

Meskhidze, N. and Nenes, A.: Phytoplankton and cloudiness in the Southern Ocean., Science, New York, N.Y., 314, 1419-23, doi:10.1126/science.1131779, 2006.

Mirme, A., Tamm, E., Mordas, G., Vana, M., Uin, J., Mirme, S., Bernotas, T., Laakso, L., Hirsikko, A., and Kulmala, M.: A widerange multi-channel air ion spectrometer, Boreal Environ. Res., 12, 247-264, 2007.

Nomura, D., Yoshikawa-Inoue, H., Toyota, T., and Shirasawa, K.: Effects of snow, snowmelting and refreezing processes on air-sea-ice $\mathrm{CO}_{2}$ flux, J. Glaciol., 56, 262-270, doi:10.3189/002214310791968548, 2010.

O’Dowd, C., McFiggans, G., Creasey, D. J., Pirjola, L., Hoell, C., Smith, M. H., Allan, B. J., Plane, J. M. C., Heard, D. E., Lee, J. D., Pilling, M. J., and Kulmala, M.: On the photochemical production of new particles in the coastal boundary layer, Geophys. Res. Lett., 26, 1707-1710, doi:10.1029/1999GL900335, 1999.

O’Dowd, C. D., Geever, M., Hill, M. K., Smith, M. H., and Jennings, S. G.: New particle formation: Nucleation rates and spatial scales in the clean marine coastal environment, Geophys. Res. Lett., 25, 1661-1664, doi:10.1029/98GL01005, 1998.

O’Dowd, C. D., Hämeri, K., Mäkelä, J. M., Pirjola, L., Kulmala, M., Jennings, S. G., Berresheim, H., Hansson, H.-C., de Leeuw, G., Kunz, G. J., Allen, A. G., Hewitt, C. N., Jackson, A., Viisanen, Y., and Hoffmann, T.: A dedicated study of New Particle
Formation and Fate in the Coastal Environment (PARFORCE): Overview of objectives and achievements, J. Geophys. Res., 107, 8108, doi:10.1029/2001jd000555, 2002a.

O’Dowd, C. D., Jimenez, J. L., Bahreini, R., Flagan, R. C., Seinfeld, J. H., Hameri, K., Pirjola, L., Kulmala, M., Jennings, S. G., and Hoffmann, T.: Marine aerosol formation from biogenic iodine emissions, Nature, 417, 632-636, doi:10.1038/nature00775, 2002b.

Pal, B. and Ariya, P. A.: Gas-Phase HO--Initiated Reactions of Elemental Mercury: Kinetics, Product Studies, and Atmospheric Implications, Environ. Sci. Technol., 38, 5555-5566, doi:10.1021/es0494353, 2004.

Park, J., Sakurai, H., Vollmers, K., and McMurry, P. H.: Aerosol size distributions measured at the South Pole during ISCAT, Atmos. Environ., 38, 5493-5500, 2004.

Pierce, J. R. and Adams, P. J.: A Computationally Efficient Aerosol Nucleation/Condensation Method: PseudoSteady-State Sulfuric Acid, Aerosol Sci. Tech., 43, 216-226, doi:10.1080/02786820802587896, 2009a.

Pierce, J. R. and Adams, P. J.: Uncertainty in global CCN concentrations from uncertain aerosol nucleation and primary emission rates, Atmos. Chem. Phys., 9, 1339-1356, doi:10.5194/acp-91339-2009, 2009b.

Pirrone, N., Cinnirella, S., Feng, X., Finkelman, R. B., Friedli, H. R., Leaner, J., Mason, R., Mukherjee, A. B., Stracher, G. B., Streets, D. G., and Telmer, K.: Global mercury emissions to the atmosphere from anthropogenic and natural sources, Atmos. Chem. Phys., 10, 5951-5964, doi:10.5194/acp-10-59512010, 2010.

Raes, F.: Entrainment of free tropospheric aerosols as a regulating mechanism for cloud condensation nuclei in the remote marine boundary layer, J. Geophys. Res., 100, 2893, doi:10.1029/94JD02832, 1995.

Rankin, A. M., Wolff, E. W., and Martin, S.: Frost flowers: Implications for tropospheric chemistry and ice core interpretation, J. Geophys. Res., 107, 4683, doi:10.1029/2002JD002492, 2002.

Reeve, J.: Aurora Australis Voyage VMS 2012/13 Track and Underway Data (SIPEX II), Australian Antarctic Data Centre, doi:10.4225/15/546580A408D97, 2013.

Robinson, A. D., Harris, N. R. P., Humphries, R. S., Kreher, K., Johnston, P. V., Thomas, A. J., and Schofield, R.: In-situ Halocarbon trace-gas concentrations measured by the $\mu$ Dirac GC-ECD during the SIPEX II voyage of the Aurora Australis, 2012. Australian Antarctic Data Centre, Australia, doi:10.4225/15/53266BB82B3A3, 2014a.

Robinson, A. D., Harris, N. R. P., Ashfold, M. J., Gostlow, B., Warwick, N. J., O’Brien, L. M., Beardmore, E. J., Nadzir, M. S. M., Phang, S. M., Samah, A. A., Ong, S., Ung, H. E., Peng, L. K., Yong, S. E., Mohamad, M., and Pyle, J. A.: Long-term halocarbon observations from a coastal and an inland site in Sabah, Malaysian Borneo, Atmos. Chem. Phys., 14, 8369-8388, doi:10.5194/acp-14-8369-2014, 2014b.

Rohrer, F. and Berresheim, H.: Strong correlation between levels of tropospheric hydroxyl radicals and solar ultraviolet radiation, Nature, 442, 184-187, doi:10.1038/nature04924, 2006.

Saiz-Lopez, A. and Plane, J. M. C.: Novel iodine chemistry in the marine boundary layer, Geophys. Res. Lett., 31, L04112, doi:10.1029/2003GL019215, 2004. 
Saiz-Lopez, A. and von Glasow, R.: Reactive halogen chemistry in the troposphere, Chem. Soc. Rev., 41, 6448-6472, doi:10.1039/c2cs35208g, 2012.

Saiz-Lopez, A., Chance, K., Liu, X., Kurosu, T. P., and Sander, S. P.: First observations of iodine oxide from space, Geophys. Res. Lett., 34, L12 812, doi:10.1029/2007g1030111, 2007a.

Saiz-Lopez, A., Mahajan, A. S., Salmon, R. A., Bauguitte, S. J. B., Jones, A. E., Roscoe, H. K., and Plane, J. M. C.: Boundary layer halogens in coastal Antarctica, Science, 317, 348-351, doi:10.1126/science.1141408, 2007b.

Schofield, R., Kreher, K., Johnston, P. V., Thomas, A. J., and Humphries, R. S.: Trace-gas profiles of the boundary layer from Multi-Axis Differential Optical Spectroscopy MAXDOAS collected during the SIPEX II voyage of the Aurora Australis, 2012, Australian Antarctic Data Centre, Australia doi:10.4225/15/53266BD1D37E6, 2014.

Schönhardt, A., Richter, A., Wittrock, F., Kirk, H., Oetjen, H., Roscoe, H. K., and Burrows, J. P.: Observations of iodine monoxide columns from satellite, Atmos. Chem. Phys., 8, 637-653, doi:10.5194/acp-8-637-2008, 2008.

Schönhardt, A., Begoin, M., Richter, A., Wittrock, F., Kaleschke, L., Gómez Martín, J. C., and Burrows, J. P.: Simultaneous satellite observations of $\mathrm{IO}$ and $\mathrm{BrO}$ over Antarctica, Atmos. Chem. Phys., 12, 6565-6580, doi:10.5194/acp-12-6565-2012, 2012.

Schroeder, W. H. and Jackson, R.: Environmental measurements with an atmospheric mercury monitor having speciation capabilities, Chemosphere, 16, 183-199, doi:10.1016/00456535(87)90123-8, 1987.

Schroeder, W. H. and Munthe, J.: Atmospheric mercury - An overview, Atmos. Environ., 32, 809-822, doi:10.1016/S13522310(97)00293-8, 1998.

Schroeder, W. H., Anlauf, K. G., Barrie, L. A., Lu, J. Y., Steffen, A., Schneeberger, D. R., and Berg, T.: Arctic springtime depletion of mercury, Nature, 394, 331-332, doi:10.1038/28530, 1998.

Seinfeld, J. H. and Pandis, S. N.: Atmospheric Chemistry and Physics - From Air Pollution to Climate Change, 2nd Edn., John Wiley \& Sons, 595-610, 2006.

Selin, N. E., Javob, D. J., Park, R. J., Yantosca, R. M., Strode, S., Jaeglé, L., and Jaffe, D.: Chemical cycling and deposition of atmospheric mercury: Global constraints from observations, J. Geophys. Res.-Atmos., 112, 1-14, doi:10.1029/2006JD007450, 2007.

Shirsat, S. V. and Graf, H. F.: An emission inventory of sulfur from anthropogenic sources in Antarctica, Atmos. Chem. Phys., 9, 3397-3408, doi:10.5194/acp-9-3397-2009, 2009.

Sihto, S.-L., Kulmala, M., Kerminen, V.-M., Dal Maso, M., Petäjä, T., Riipinen, I., Korhonen, H., Arnold, F., Janson, R., Boy, M., Laaksonen, A., and Lehtinen, K. E. J.: Atmospheric sulphuric acid and aerosol formation: implications from atmospheric measurements for nucleation and early growth mechanisms, Atmos. Chem. Phys., 6, 4079-4091, doi:10.5194/acp-6-4079-2006, 2006.

Simpson, W. R., Carlson, D., Hönninger, G., Douglas, T. A., Sturm, M., Perovich, D., and Platt, U.: First-year sea-ice contact predicts bromine monoxide $(\mathrm{BrO})$ levels at Barrow, Alaska better than potential frost flower contact, Atmos. Chem. Phys., 7, 621-627, doi:10.5194/acp-7-621-2007, 2007.
Slemr, F., Schuster, G., and Seiler, W.: Distribution, speciation, and budget of atmospheric mercury, J. Atmos. Chem., 3, 407-434, doi:10.1007/BF00053870, 1985.

Slemr, F., Brunke, E.-G., Ebinghaus, R., Temme, C., Munthe, J., Wängberg, I., Schroeder, W., Steffen, A., and Berg, T.: Worldwide trend of atmospheric mercury since 1977, Geophys. Res. Lett., 30, doi:10.1029/2003GL016954, 2003.

Slemr, F., Brunke, E.-G., Ebinghaus, R., and Kuss, J.: Worldwide trend of atmospheric mercury since 1995, Atmos. Chem. Phys., 11, 4779-4787, doi:10.5194/acp-11-4779-2011, 2011.

Slemr, F., Angot, H., Dommergue, A., Magand, O., Barret, M. Weigelt, A., Ebinghaus, R., Brunke, E.-G., Pfaffhuber, K. A., Edwards, G., Howard, D., Powell, J., Keywood, M., and Wang, F.: Comparison of mercury concentrations measured at several sites in the Southern Hemisphere, Atmos. Chem. Phys., 15, 31253133, doi:10.5194/acp-15-3125-2015, 2015.

Snider, G., Raofie, F., and Ariya, P. A.: Effects of relative humidity and $\mathrm{CO}(\mathrm{g})$ on the $\mathrm{O}_{3}$-initiated oxidation reaction of $\mathrm{Hg} 0(\mathrm{~g})$ : kinetic \& product studies, Phys. Chem. Chem. Phys., 10, 56165623, doi:10.1039/B801226A, 2008.

Stephens, C. R., Shepson, P. B., Steffen, A., Bottenheim, J. W., Liao, J., Huey, L. G., Apel, E., Weinheimer, A., Hall, S. R., Cantrell, C., Sive, B. C., Knapp, D. J., Montzka, D. D., and Hornbrook, R. S.: The relative importance of chlorine and bromine radicals in the oxidation of atmospheric mercury at Barrow, Alaska, J. Geophys. Res.-Atmos., 117, D00R11, doi:10.1029/2011JD016649, 2012.

United Nations Environmental Programme: The Global Atmospheric Mercury Assessment: Sources, Emissions and Transport, Tech. rep., United National Environment Programme, http://www.unep.org/chemicalsandwaste/ Portals/9/Mercury/Documents/Publications/UNEP_ GlobalAtmosphericMercuryAssessment_May2009.pdf （last access: 30 November 2015), 2008.

United Nations Environmental Programme: Global Mercury Assessment 2013: Sources, Emissions, Releases, and Environmental Transport, Tech. rep., http://www.unep.org/PDF/ PressReleases/GlobalMercuryAssessment2013.pdf (last access: 30 November 2015) 2013.

von der Weiden, S.-L., Drewnick, F., and Borrmann, S.: Particle Loss Calculator - a new software tool for the assessment of the performance of aerosol inlet systems, Atmos. Meas. Tech., 2, 479-494, doi:10.5194/amt-2-479-2009, 2009.

Warren, D. R. and Seinfeld, J. H.: Prediction of aerosol concentrations resulting from a burst of nucleation, J. Colloid and Interf Sci., 105, 136-142, doi:10.1016/0021-9797(85)90356-X, 1985.

Wilson, S. R.: Characterisation of $J\left(\mathrm{O}^{1} \mathrm{D}\right)$ at Cape Grim 2000 2005, Atmos. Chem. Phys., 15, 7337-7349, doi:10.5194/acp-157337-2015, 2015.

Yang, X., Pyle, J. A., and Cox, R. A.: Sea salt aerosol production and bromine release: Role of snow on sea ice, Geophys. Res. Lett., 35, L16815, doi:10.1029/2008GL034536, 2008.

Yu, F.: From molecular clusters to nanoparticles: second-generation ion-mediated nucleation model, Atmos. Chem. Phys., 6, 51935211, doi:10.5194/acp-6-5193-2006, 2006.

$\mathrm{Yu}, \mathrm{F}$. Ion-mediated nucleation in the atmosphere: Key controlling parameters, implications, and look-up table, J. Geophys. Res., 115, D03206, doi:10.1029/2009JD012630, 2010. 
Yu, F. and Turco, R. P.: Ultrafine aerosol formation via ion-mediated nucleation, Geophys. Res. Lett., 27, 883-886, doi:10.1029/1999GL011151, 2000.

Yu, F., Luo, G., Bates, T. S., Anderson, B., Clarke, A., Kapustin, V., Yantosca, R. M., Wang, Y., and Wu, S.: Spatial distributions of particle number concentrations in the global troposphere: Simulations, observations, and implications for nucleation mechanisms, J. Geophys. Res., 115, D17205, doi:10.1029/2009JD013473, 2010.
Zhao, J., Eisele, F. L., Titcombe, M., Kuang, C., and McMurry, P. H.: Chemical ionization mass spectrometric measurements of atmospheric neutral clusters using the cluster-CIMS, J. Geophys. Res., 115, D08205, doi:10.1029/2009JD012606, 2010. 